\title{
CRK proteins selectively regulate T cell migration into inflamed tissues
}

\author{
Yanping Huang, ${ }^{1}$ Fiona Clarke, ${ }^{1}$ Mobin Karimi, ${ }^{2}$ Nathan H. Roy, ${ }^{1}$ Edward K. Williamson, ${ }^{1}$ Mariko Okumura, ${ }^{2}$ Kazuhiro Mochizuki, ${ }^{3}$ \\ Emily J.H. Chen, ${ }^{1}$ Tae-Ju Park, ${ }^{1}$ Gudrun F. Debes, ${ }^{4}$ Yi Zhang, ${ }^{3}$ Tom Curran, ${ }^{1,2}$ Taku Kambayashi, ${ }^{2}$ and Janis K. Burkhardtt, \\ 'Department of Pathology and Laboratory Medicine, The Children's Hospital of Philadelphia, Philadelphia, Pennsylvania, USA. 'Department of Pathology and Laboratory Medicine, Perelman School \\ of Medicine at the University of Pennsylvania, Philadelphia, Pennsylvania, USA. ${ }^{3}$ Department of Internal Medicine, University of Michigan Medical School, Ann Arbor, Michigan, USA. \\ ${ }^{4}$ Department of Pathobiology, University of Pennsylvania School of Veterinary Medicine, Philadelphia, Pennsylvania, USA.
}

\begin{abstract}
Effector T cell migration into inflamed sites greatly exacerbates tissue destruction and disease severity in inflammatory diseases, including graft-versus-host disease (GVHD). T cell migration into such sites depends heavily on regulated adhesion and migration, but the signaling pathways that coordinate these functions downstream of chemokine receptors are largely unknown. Using conditional knockout mice, we found that T cells lacking the adaptor proteins CRK and CRK-like (CRKL) exhibit reduced integrin-dependent adhesion, chemotaxis, and diapedesis. Moreover, these two closely related proteins exhibited substantial functional redundancy, as ectopic expression of either protein rescued defects in T cells lacking both CRK and CRKL. We determined that CRK proteins coordinate with the RAP guanine nucleotide exchange factor C3C and the adhesion docking molecule CASL to activate the integrin regulatory GTPase RAP1. CRK proteins were required for effector T cell trafficking into sites of inflammation, but not for migration to lymphoid organs. In a murine bone marrow transplantation model, the differential migration of CRK/CRKL-deficient T cells resulted in efficient graft-versus-leukemia responses with minimal CVHD. Together, the results from our studies show that CRK family proteins selectively regulate $\mathrm{T}$ cell adhesion and migration at effector sites and suggest that these proteins have potential as therapeutic targets for preventing GVHD.
\end{abstract}

\section{Introduction}

$\mathrm{T}$ cells continuously recirculate to perform immune surveillance and effector functions. Within lymph nodes, naive T cells extravasate preferentially through high endothelial venules (HEVs) to survey dendritic cells for foreign antigens. If they fail to encounter cognate antigens, they recirculate to the blood via the efferent lymph. If they encounter cognate antigens, $\mathrm{T}$ cells undergo clonal expansion and changes in receptor expression that allow trafficking to first-barrier organs (e.g., skin or the gut mucosa), which they reach by crossing postcapillary venules (1). Transendothelial migration involves multiple steps: selectin-mediated rolling, chemokine-triggered integrin activation and consequent firm adhesion, migration along the endothelial wall, and passage through the endothelial barrier (2). Each step is tightly regulated by membrane receptors on the $\mathrm{T}$ cell and the interacting endothelial cells. Chemokine receptors play a pivotal role, triggering rapid changes in T cell adhesion and cytoskeletal remodeling. Although crucial for adaptive immune responses to invading pathogens, $\mathrm{T}$ cell migration into peripheral tissues can also lead to inflammation and tissue destruction. For example, in patients receiving allogeneic bone marrow transplants, infiltration of donor $\mathrm{T}$ cells leads to graft-versus-host disease (GVHD), a life-threatening complication (3). Thus, molecules that regulate $\mathrm{T}$ cell tissue infiltration are important therapeutic targets.

Conflict of interest: The authors have declared that no conflict of interest exists Submitted: June 27, 2014; Accepted: December 11, 2014.

Reference information: J Clin Invest. 2015;125(3):1019-1032. doi:10.1172/JCI77278.
CRK proteins are key regulators of adhesion and migration in many cell types. This family of ubiquitously expressed adaptors consists of CRKI, CRKII (products of the CRK gene), and CRKlike (CRKL), encoded by an independent gene, CRKL. CRKII and CRKL contain one SH2 domain followed by two SH3 domains (designated nSH3 and cSH3), whereas the splice variant CRKI lacks the $\mathrm{cSH} 3$ domain. The nSH3 domain of CRK proteins binds to C3G and DOCK180, which are guanine-nucleotide exchange factors (GEFs) for the small GTPases RAP1 and RAC1, respectively (4). RAP1 controls adhesion, while RAC1 controls actin polymerization. Binding of the $\mathrm{SH} 2$ domain of CRK proteins with p130Cas/CASL/EFS family proteins is important for localization of CRK to the plasma membrane $(4,5)$. In contrast to the nSH3 and $\mathrm{SH} 2$ domains, the cSH3 domain of CRKII engages in intramolecular interactions that negatively regulate CRKII function by stabilizing a closed, autoinhibited state (6). In addition, CRKII and CRKL have a regulatory tyrosine (Y221 in CRKII, Y207 in CRKL) that is phosphorylated by ABL family kinases $(7,8)$. Phosphorylation of CRKII at Y221 creates a binding site for the SH2 domain, and the resulting intramolecular interaction blocks accessibility of the SH2 and nSH3 domains to other binding partners and terminates CRKII signaling (7). CRKI, which lacks the regulatory cSH3 domain and phosphorylation site, exhibits constitutively active adaptor function $(4,9)$.

Despite their importance in other cell types, the function of CRK proteins in T cells is poorly understood. Progress in this area has been hindered by the existence of profound developmental abnormalities in mice with germline deletion of CRK proteins 
A

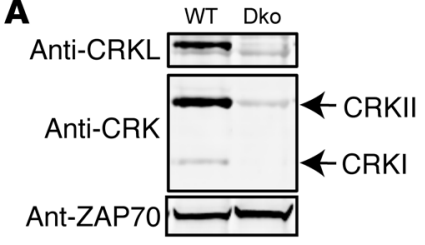

B

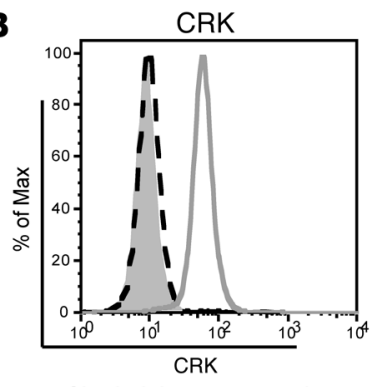

Shaded: isotype control Solid line: WT Dashed line: Dko

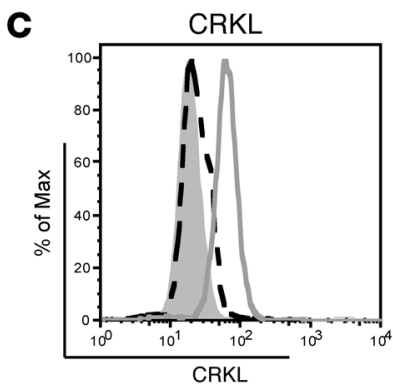

D

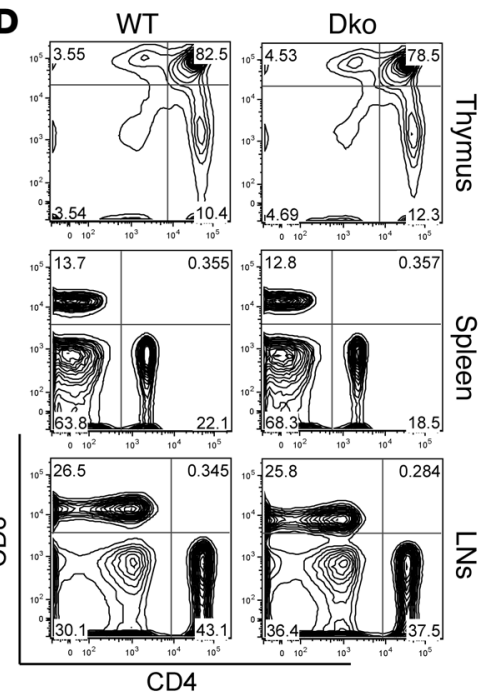

E

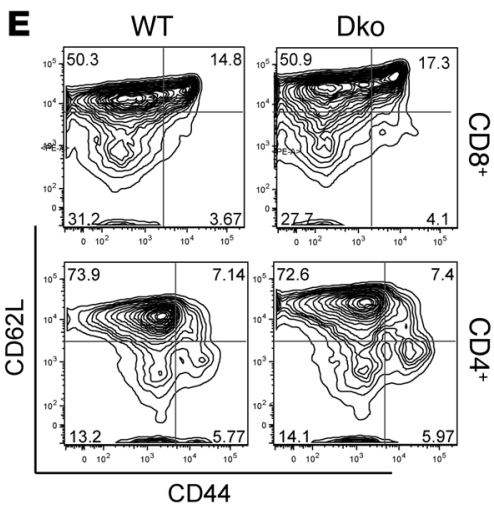

Figure 1. Crk and Crkl are deleted in T cells of CRK/CRKL Dko mice. (A) CD4 ${ }^{+} \mathrm{T}$ cells were purified from lymph nodes of CRK/ CRKL DKo and WT mice. Preactivated T cells were prepared by stimulating with plate-bound anti-CD3 and anti-CD28 for 2 days and culturing without stimuli for an additional 5 days. Whole cell lysates were analyzed by SDS-PACE and immunoblotted with antiCRKL, anti-CRK, and anti-ZAP70. (B) (C) Preactivated CD4+ ${ }^{+}$cells made as in $\mathbf{A}$ were fixed and permeabilized, and the intracellular staining of CRK (B) and CRKL (C) was determined by flow cytometry. (D) Thymus, spleens, and lymph nodes (LNs) were isolated from WT and CRK/CRKL Dko mice. Single-cell suspensions were analyzed by flow cytometry using the indicated antibodies. (E) Gated $\mathrm{CD} 4^{+}$and $\mathrm{CD} 8^{+} \mathrm{T}$ cells from lymph nodes (mixed peripheral and mesenteric lymph nodes) were analyzed for the indicated surface markers.

therapeutic implications, since they can carry out graftversus-leukemia (GVL) responses with minimal GVHD.

\section{Results}

Generation and characterization of $T$ cell-specific CRK/ CRKL-deficient mice. To delete the Crk and Crkl genes in mature T cells, we bred mice bearing loxP-flanked Crk and $\mathrm{Crkl}$ alleles (14) with $\mathrm{Cd} 4$-Cre transgenic mice $\left(\mathrm{Crk}^{\mathrm{f} / \mathrm{A} / \mathrm{Crk}} \mathrm{Cr}^{\mathrm{l} / \mathrm{l}}\right.$ Cd4-Cre mice; hereafter called CRK/CRK Dko mice). Some strains were further crossed to Rosa26-EYFP mice to monitor Cre expression (15). Analysis of CRK/CRK Dko Rosa-EYFP mice showed that Cre expression was present in 95\% of peripheral $\mathrm{CD} 4^{+}$and $\mathrm{CD} 8^{+} \mathrm{T}$ cells (data not shown). Western blotting of purified $\mathrm{CD} 4^{+} \mathrm{T}$ cells from Dko and WT mice revealed that levels of CRKI, CRKII, and CRKL in the mutant $\mathrm{T}$ cells were reduced by at least $95 \%$ (Figure $1 \mathrm{~A}$ and data not shown), and flow cytometric analysis confirmed

(the majority of Crk-null and Crkl-null mice die during embryonic development; refs. 10,11) and by problems posed by functional redundancy. The few studies that have been performed have focused on the T cell receptor (TCR) signaling pathway, and results are conflicting. Using the small number of surviving $\mathrm{Crkl}^{-1}$ mice, Peterson et al. showed that thymocyte number was reduced, but $\mathrm{T}$ cell differentiation and activation were intact (12). In contrast, Nolz et al. used RNAi to suppress CRKL expression in Jurkat cells and ex vivo human $\mathrm{T}$ cells and observed defects in integrin activation and cytokine production downstream of TCR engagement (13). Neither study addressed chemokine-dependent $\mathrm{T}$ cell responses, and neither addressed possible functional redundancy between CRKL and the closely related proteins CRKI and CRKII.

To circumvent developmental problems and allow analysis of $T$ cells lacking all CRK proteins, we used mice bearing floxed alleles of both Crk and Crkl. These mice have been used successfully to delete $\mathrm{Crk}$ and $\mathrm{Crkl}$ in neuronal progenitor cells, resulting in defects in the Reelin signaling pathway and failure of neuronal migration (14). We now show that conditional deletion of Crk and Crkl genes late in T cell development leads to impaired activation of RAP1 and defective adhesion, chemotaxis, and diapedesis. Interestingly, we found that CRK/CRKL-deficient $\mathrm{T}$ cells show selective trafficking defects in vivo; these cells homed efficiently to lymphoid organs but migrated poorly to sites of inflammation. The differential migratory activity of CRK/CRKL-deficient $\mathrm{T}$ cells has important loss of CRK protein expression (Figure 1, B and C).

CRK/CRKL Dko mice were born at Mendelian ratios, and spleen, thymus, and lymph nodes exhibited normal cellularity (data not shown). Thymocyte populations were similar in WT and Dko mice, indicating that $\mathrm{T}$ cell development proceeded normally (Figure 1D). Peripheral lymphoid organs showed no differences in proportions of $\mathrm{CD}^{+}$and $\mathrm{CD} 8^{+} \mathrm{T}$ cells, naive $\left(\mathrm{CD} 62 \mathrm{~L}^{\mathrm{hi}}\right.$ CD44 $\left.4^{\text {lo }}\right)$, memory $\left(\mathrm{CD} 62 \mathrm{~L}^{\mathrm{lo}} \mathrm{CD} 44^{\mathrm{hi}}\right)$, or activated $\left(\mathrm{CD} 69^{\mathrm{hi}}\right) \mathrm{T}$ cell subsets (Figure 1, D and E, and data not shown). Thus, these mice represented a suitable source of mature CRK/CRKL Dko $\mathrm{T}$ cells for functional studies.

CRK/CRKL-deficient $T$ cells show defects in adhesion and polarization. Since CRK proteins control adhesion in non-hematopoietic cells (4), we first asked whether integrin-dependent adhesion is defective in CRK/CRKL Dko T cells. On plates coated with ICAM-1, the ligand for the $\beta_{2}$ integrin LFA-1, WT preactivated CD $4^{+}$T cells showed about $10 \%$ basal binding, which was increased 2- to 5 -fold after stimulation with the chemokines CXCL12 or CCL21, or antiCD3 (Figure 2A). CRK/CRKL Dko T cells showed a significant reduction in adhesion to ICAM-1 under both basal and stimulated conditions. Indeed, chemokine stimulation induced almost no increased adhesion in these cells. Treatment with PMA bypassed the defect. This is most likely because the defect in CRK/CRKL Dko cells lies upstream of PKC signaling in the pathway leading to integrin activation, though PKC activation could also drive a parallel 

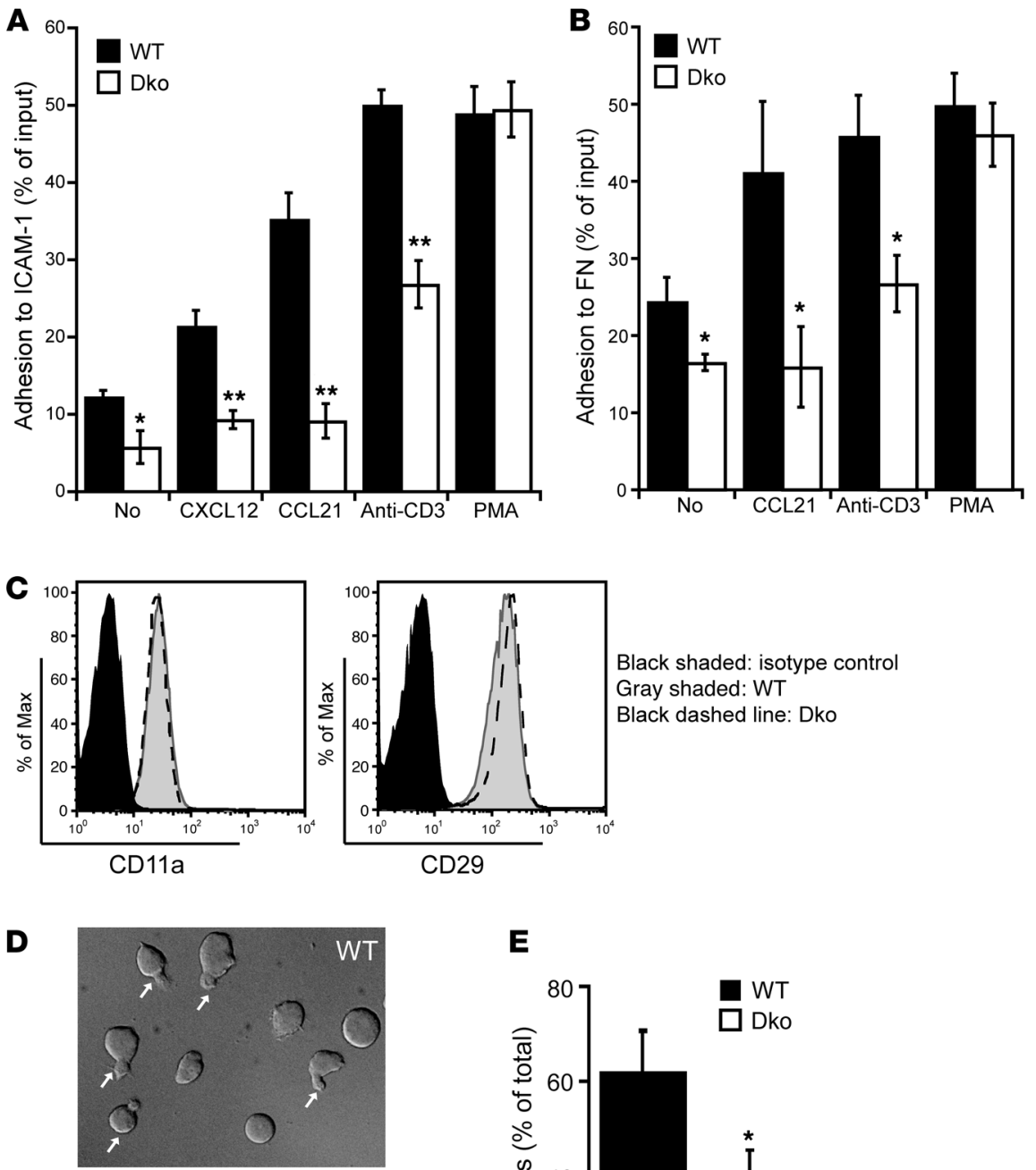

D
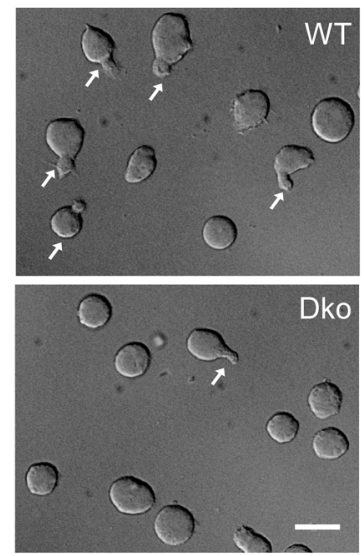

Dko

pathway (16). Similar adhesion defects were observed in response to fibronectin, a ligand for the $\beta_{1}$ integrin VLA-4 (Figure 2B). These defects were not attributable to altered integrin expression, since CRK/CRKL Dko T cells expressed normal surface levels of the CD11a chain of LFA-1 and the CD29 chain of VLA-4 (Figure 2C).

Binding to integrins induces $\mathrm{T}$ cell polarization, a process that sets the stage for motility (17). This event, too, was reduced in integrin-stimulated CRK/CRKL Dko cells (Figure 2, D and E). This phenotype does not represent a general polarity defect, since CRK/CRKL Dko T cell blasts formed well-developed uropods in response to anti-CD3/anti-CD28 stimulation (data not shown). Together, these results show that CRK proteins are required for efficient integrin-dependent $\mathrm{T}$ cell adhesion and downstream events leading to cell polarity.

$C R K$ and CRKL are required for efficient $T$ cell chemotaxis. We next asked whether CRK and CRKL are important for $\mathrm{T}$ cell migration using a Transwell-based chemotaxis assay. As shown in Fig-
Figure 2. CRK/CRKL-deficient T cells show impaired integrin-dependent adhesion. Ninetysix-well plates were coated with $1 \mu \mathrm{g} / \mathrm{ml}$ recombinant mouse ICAM-1 (A) or $3 \mu \mathrm{g} / \mathrm{ml}$ fibronectin (FN) (B). Preactivated WT and CRK/CRKL Dko $\mathrm{CD}^{+} \mathrm{T}$ cells were stained with Calcein-AM, applied to ICAM-1- or fibronectin-coated plates, and allowed to warm to $37^{\circ} \mathrm{C}$ for 10 minutes without stimulus (No) or in the presence of $10 \mathrm{nM} \mathrm{CXCL12,}$ $10 \mathrm{nM} \mathrm{CCL21,} 1 \mu \mathrm{g} / \mathrm{ml}$ anti-CD3, or $10 \mathrm{ng} / \mathrm{ml}$ PMA. Unbound cells were washed off, and adherent cells were quantified using a fluorescence microplate reader. Data represent averages \pm SD of triplicate samples from 1 experiment, representative of 5 separate experiments. ${ }^{*} P<0.05$, ${ }^{*} P<0.01$. (C) Preactivated WT and CRK/CRKL Dko CD4 ${ }^{+} T$ cells were stained with anti-CD11a-FITC or anti-CD29PE and analyzed by flow cytometry. Representative data from 3 experiments are shown. ( $\mathbf{D}$ and E) Preactivated WT and CRK/CRKL Dko CD4 ${ }^{+} \mathrm{T}$ cells were applied to fibronectin-coated coverslips. After incubation at $37^{\circ} \mathrm{C}$ for 30 minutes, cells were fixed and analyzed by differential interference contrast (DIC) microscopy. Arrows indicate polarized T cells with a clear uropod. (E) Cells prepared as in $\mathbf{D}$ were quantified. Data are average \pm SD values from 3 experiments, totaling 433 cells for WT and 387 for CRK/CRKL Dko. ${ }^{*} P<0.05$. Scale bar: $20 \mu \mathrm{m}$. Statistical analysis was performed using paired (A and $\mathbf{B}$ ) or unpaired (E) 2-tailed Student's $t$ tests. ure 3, A and B, WT CD4 ${ }^{+} \mathrm{T}$ cells chemotaxed efficiently toward both CCL21 and CXCL10, chemokines that signal naive T cell trafficking into lymph nodes $(18,19)$ and Th1 cell trafficking to sites of inflammation (20), respectively. In contrast, CRK/CRKL Dko $\mathrm{T}$ cells displayed $20 \%-50 \%$ less migration toward both chemokines. These defects were not due to differences in the surface expression of the relevant chemokine receptors CCR7 and CXCR3 (Figure 3C). Similar results were obtained with CXCL12, a CXCR4 ligand that cooperates with CCR7 ligands to promote naive $\mathrm{T}$ cell trafficking across HEVs (ref. 21 and data not shown).

Since 2D migration (including Transwell assays) involves integrin function, we also tested chemotaxis in 3D collagen gels, where migration is integrin independent (22). Interestingly, CRK/CRKL Dko T cells chemotaxed efficiently toward both CCL19 and CCL21 in this setting (Figure 3D and Table 1). Comparison of multiple parameters including velocity, directionality, and forward migration index showed no significant differences between mutant and 

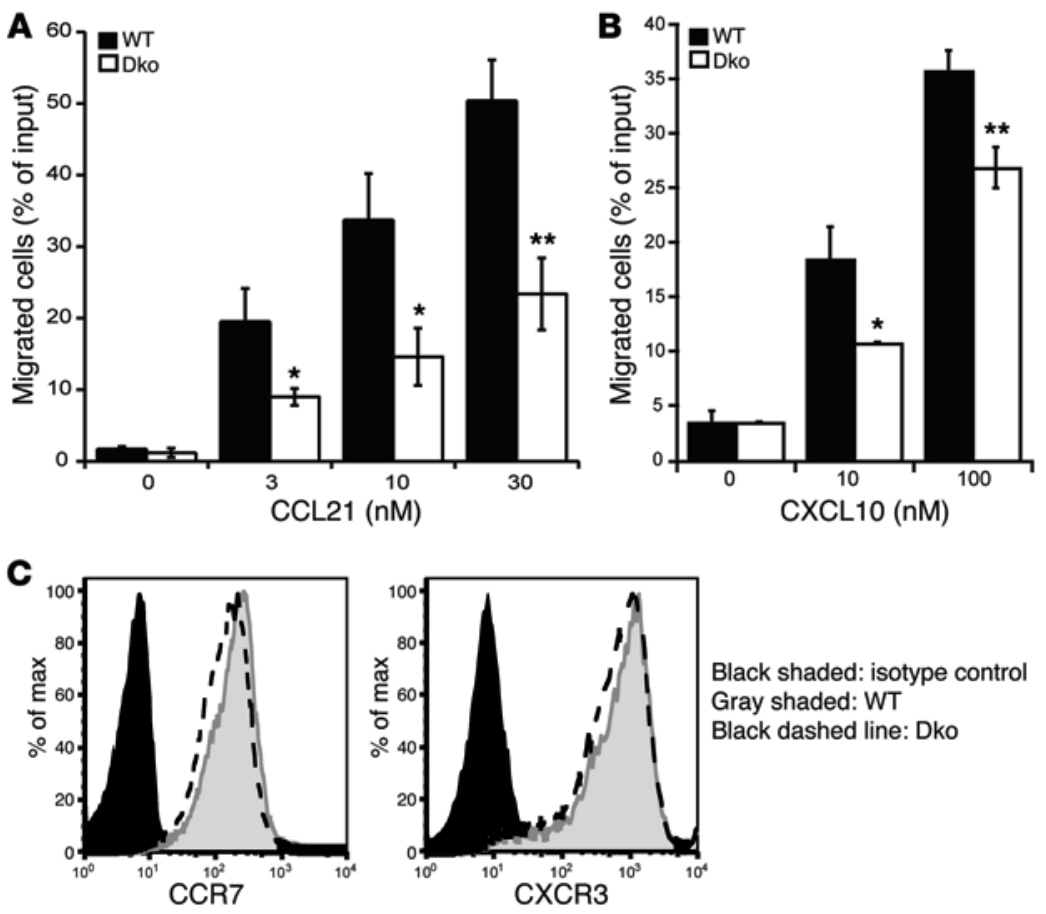

Black shaded: isotype contro Gray shaded: WT Black dashed line: Dko
D

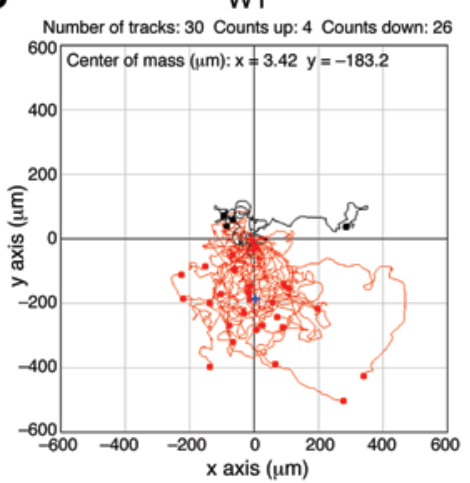

Dko

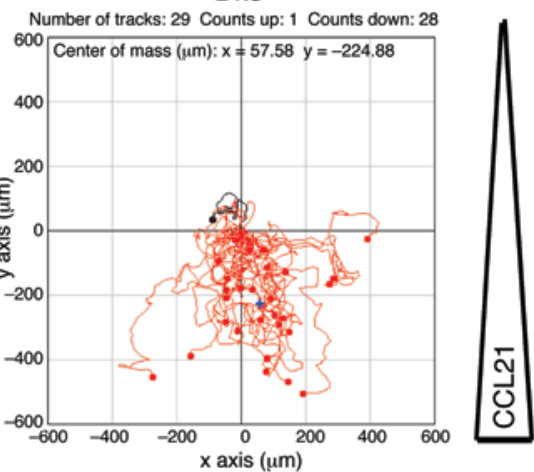

Figure 3. CRK/CRKL-deficient T cells show defects in chemotaxis. Preactivated WT and CRK/CRKL Dko CD4 ${ }^{+}$ $T$ cells were prepared, and migration in response to CCL21 (A) or CXCL10 (B) was tested by using a $3-\mu \mathrm{m}$-pore-size Transwell chamber. Average \pm SD values from quadruplicate wells from 1 experiment, representative of 5 separate experiments, are shown. ${ }^{*} P<0.05$, ${ }^{* *} P<0.01$. Statistical analysis was performed using paired 2-tailed Student's $t$ tests. (C) Flow cytometric analysis of chemokine receptor expression. Left: Preactivated WT and CRK/CRKL Dko CD4+ $T$ cells were incubated with recombinant mouse CCL19-Fc, followed by labeling with anti-human Fcy-biotin, then streptavidin$\mathrm{PE}$, to detect CCR7 surface expression. Right: Preactivated WT and CRK/CRKL Dko CD4 ${ }^{+} T$ cells were stained with anti-CXCR3-PE. (D) Preactivated WT or CRK/CRKL Dko CD4 ${ }^{+} T$ cells were placed in a $5-\mu \mathrm{m}$-pore collagen gel in the presence of a CCL21 gradient, and cell migration was imaged for 4 hours at $37^{\circ} \mathrm{C}$. Tracks of individual cells are presented with the same point of origin. Data are representative of 3 experiments. Quantitative analysis of cell movements is shown in Table 1. Tracks in $\mathbf{D}$ are from experiment 3.
WT cells. Thus, we conclude that loss of CRK proteins primarily impairs adhesion-dependent $\mathrm{T}$ cell migration; chemokine sensing is intact, and the response is sufficient to induce directional migration in settings where integrin-dependent adhesion is not required.

CRK/CRKL-deficient $T$ cells are defective in diapedesis. Firm adhesion is a prerequisite for $\mathrm{T}$ cells to transmigrate through the endothelial wall (extravasation/diapedesis) (2). To ask whether CRK proteins regulate diapedesis, T cells were monitored by time-lapse imaging while interacting with endothelial monolayers (untreated, or previously treated with TNF- $\alpha$ to upregulate ICAM-1 and VCAM-1 expression; data not shown). In this assay, cells that pass through the endothelial monolayer become phase-dark and flattened (see Supplemental Videos 1 and 2; supplemental material available online with this article; doi:10.1172/ JCI77278DS1). Figure 4A shows a WT T cell undergoing diapedesis and a CRK/CRKL Dko cell that remained on the top of the monolayer. Quantitative analysis revealed that WT T cells showed robust diapedesis across TNF- $\alpha$-treated endothelia, but CRK/CRKL Dko cells exhibited major defects (Figure 4B). Similar results were obtained using in vitro generated CRK/CRKL Dko Th1 cells (data not shown) and using an alternate assay in which endothelial cells were grown on Transwell inserts (Figure 4C).

Table 1. Chemotaxis in 3D collagen gels

$\begin{array}{lccc} & \begin{array}{c}y \text { Forward migration } \\ \text { index }\end{array} & \text { Directionality } & \text { Velocity (mean } \pm \text { SD) } \\ \text { Experiment 1, CCL19 } & & & \\ \text { WT } & -0.22 & 0.37 & 9.6 \pm 3.0 \mu \mathrm{m} / \mathrm{min} \\ \text { Dko } & -0.22 & 0.32 & 10.8 \pm 3.0 \mu \mathrm{m} / \mathrm{min} \\ \text { Experiment 2, CCL19 } & & & \\ \text { WT } & -0.26 & 0.33 & 8.6 \pm 2.5 \mu \mathrm{m} / \mathrm{min} \\ \text { Dko } & -0.25 & 0.33 & 8.3 \pm 2.8 \mu \mathrm{m} / \mathrm{min} \\ \text { Experiment 3, CCL21 } & & & \\ \text { WT } & -0.24 & 0.33 & 8.6 \pm 3.3 \mu \mathrm{m} / \mathrm{min} \\ \text { Dko } & -0.28 & 0.33 & 9.1 \pm 3.0 \mu \mathrm{m} / \mathrm{min} \\ \end{array}$


A
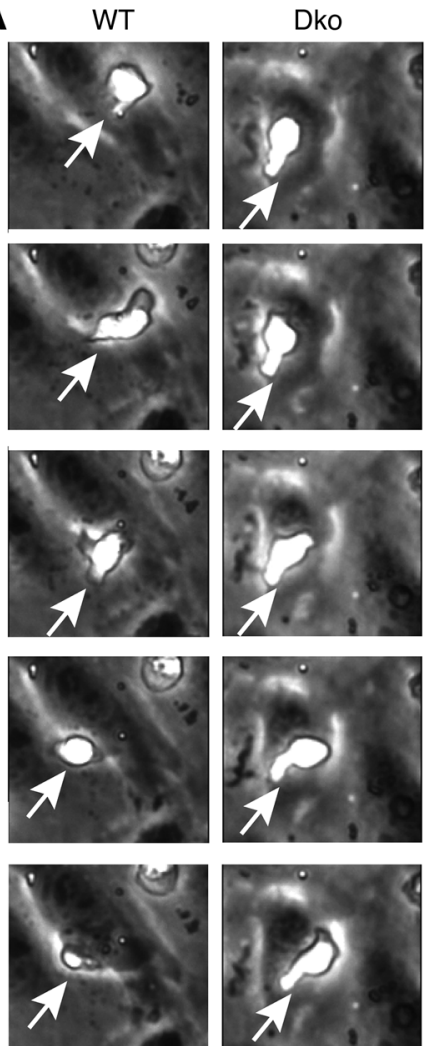

Time

(min)

0.0

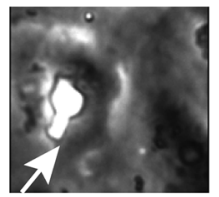

0.5

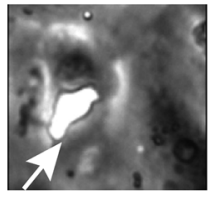

1.0
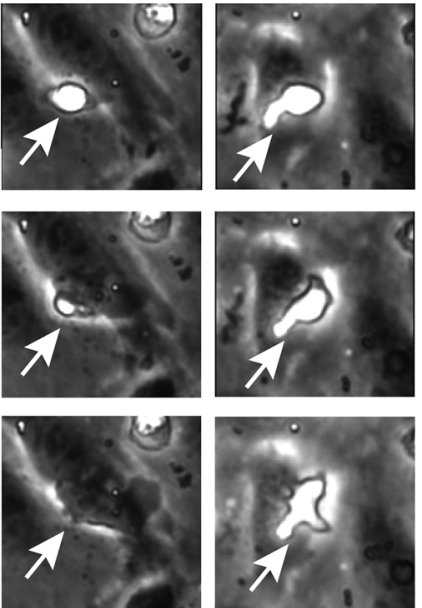

2.0

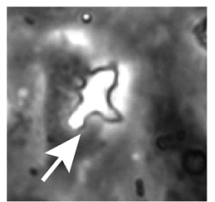

B

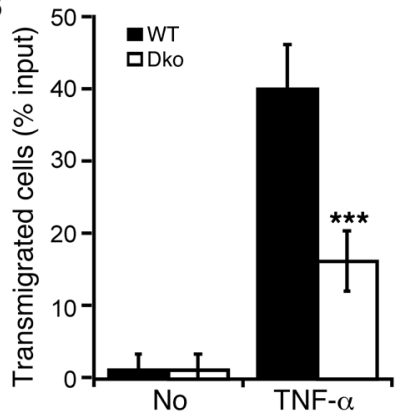

C

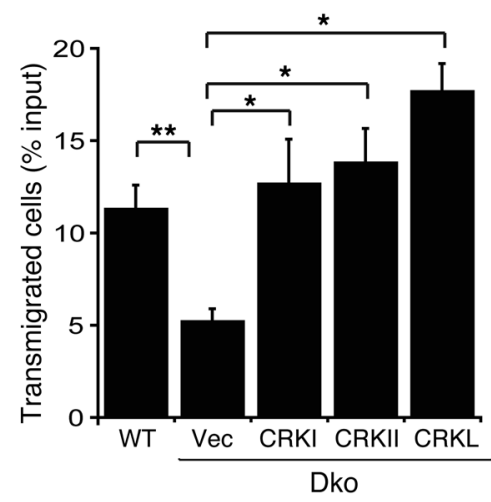

D

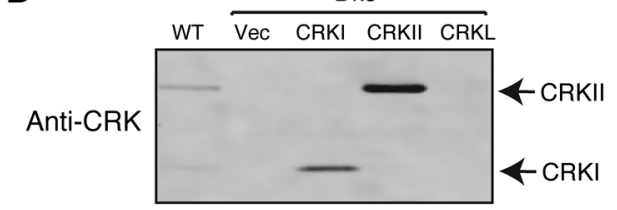

Anti-CRKL

Anti-ZAP70

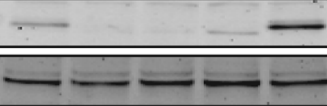

E

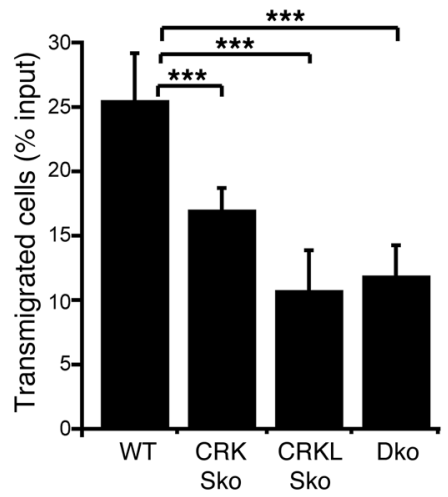

Figure 4. CRIK/CRIKL-deficient T cells show defects in diapedesis. ( $A$ and B) 3B-11 endothelial cell monolayers were treated with TNF- $\alpha$ overnight, and preactivated WT or CRK/CRKL Dko CD4+ $T$ cells were added on top. Images were collected every 30 seconds for 2 hours. Selected time-lapse images of WT T cells (left, arrows) and CRK/CRKL Dko T cells (right, arrows) acquired at the indicated time points are shown (A). T cells that transmigrated across the endothelial monolayer were scored, and average \pm SD values from 4 different experiments are shown. A total of 80 cells per genotype were scored (B). (C) $3 \mathrm{~B}-11$ cells were grown as a monolayer on top of Transwell inserts and treated with TNF- $\alpha$. CRK/CRKL DKo CD4+ $T$ cells were reconstituted with the indicated CRK isoforms and applied to the Transwell inserts. T cells that underwent diapedesis were collected and analyzed by flow cytometry. (D) Cells used in C were blotted with the indicated antibodies. Data represent mean \pm SD for triplicate samples from 1 experiment, representative of 4 independent experiments. (E) Preactivated $\mathrm{CD} 4^{+} \mathrm{T}$ cells prepared from mice that were singly deficient (Sko) for either CRK or CRKL were applied to 3B-11 monolayers on Transwell inserts, and T cell diapedesis was assessed as in C. Data represent mean \pm SD from 3 independent experiments. ${ }^{*} P<0.05$, ${ }^{*} P<0.01,{ }^{* * *} P<0.005$. Statistical analysis was performed using unpaired (B) or paired (C and E) 2-tailed Student's $t$ tests.
CRK and CRKL have partially overlapping function. Since the Transwell-based diapedesis assay showed robust and reproducible defects in CRK/CRKL Dko T cells, we used this assay to test functional redundancy among the $3 \mathrm{CRK}$ isoforms. First, CRK/ CRKL Dko CD4 ${ }^{+} \mathrm{T}$ cells were retrovirally reconstituted with CRKI, CRKII, or CRKL. As shown in Figure 4C, ectopic expression of any individual CRK isoform could fully rescue diapedesis, indicating overlapping function among CRK proteins. Retroviral transduction yielded 5 - to 10 -fold overexpression relative to endogenous protein levels (Figure 4D and data not shown), raising the possibility that this result stemmed from CRK protein overexpression. Thus, we also tested $\mathrm{T}$ cells from CRK or CRKL single knockout mice. These cells showed no compensatory changes in CRK protein expression (data not shown). As shown in Figure 4E, T cells lacking either CRK or CRKL alone showed defective diapedesis. CRKL-deficient T cells showed a more profound defect, similar in magnitude to that in Dko T cells. Thus, we conclude that CRK and CRKL are both required for optimal $\mathrm{T}$ cell diapedesis, with CRKL playing a more prominent role.

$C R K$ and CRKL selectively promote activation of RAP1 and $C D C 42$. We next asked what molecular pathways are controlled by CRK and CRKL to promote T cell adhesion and migration. No differences were observed between CRK/CRKL Dko T cells and WT cells in CCL21-induced ERK phosphorylation (Figure 5A), demonstrating that by this measure, Dko T cells respond to chemokine receptor stimulation as well as WT T cells. In non-hematopoietic 
A
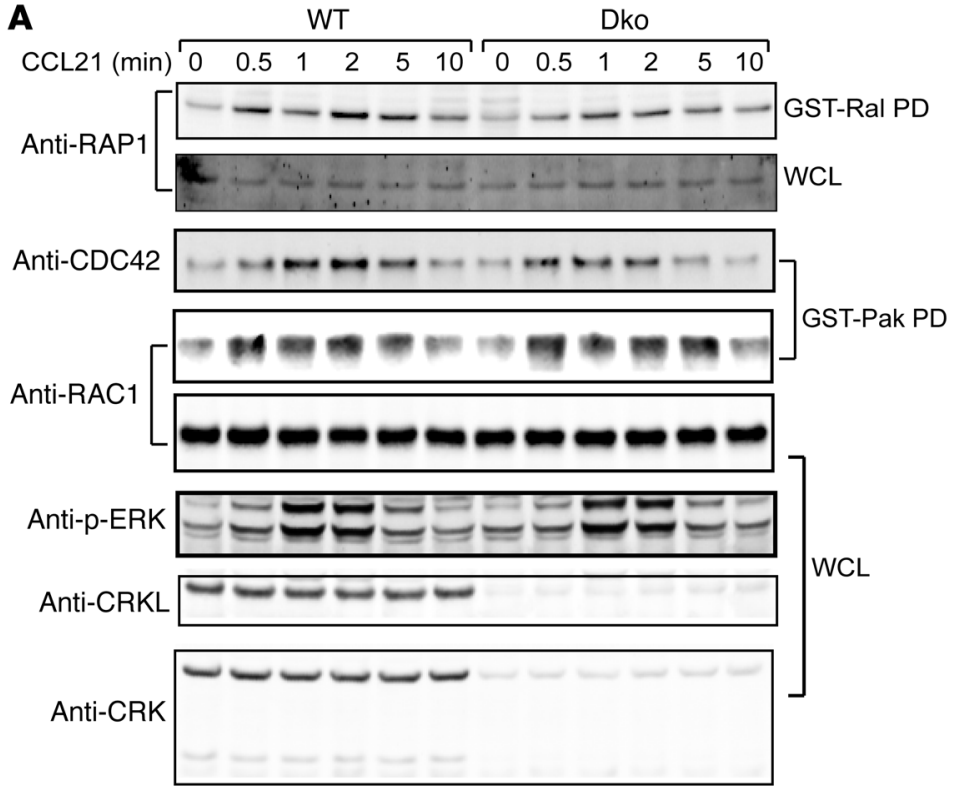

B

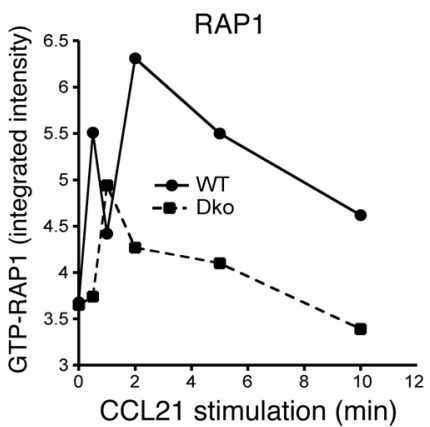

C

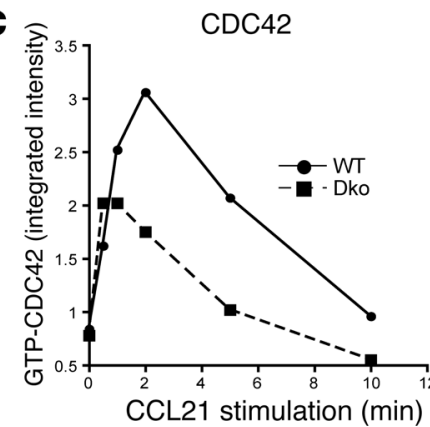

D
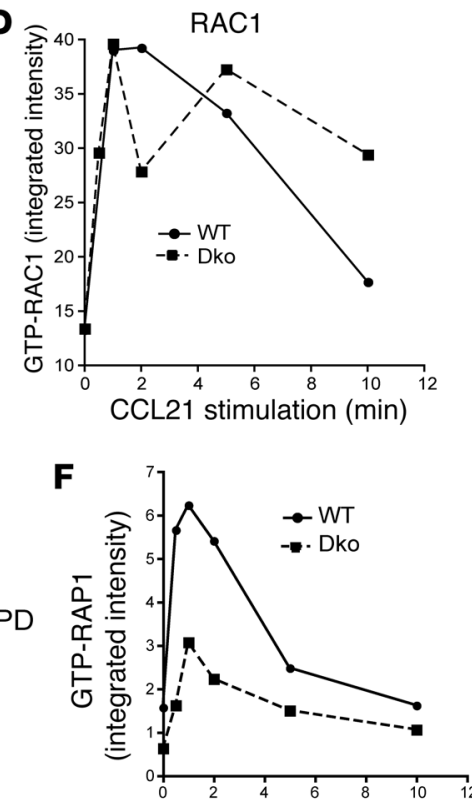

Figure 5. RAC1 activation is intact, but RAP1 and CDC42 activation is defective in CRK/CRKL-deficient T cells. (A) Prewith $10 \mathrm{nM} \mathrm{CCL21} \mathrm{for} \mathrm{the} \mathrm{indicated} \mathrm{times.} \mathrm{Whole} \mathrm{cell} \mathrm{lysates}$ (WCL) were subjected to pull-down with GST-RaIGDS (GSTRal PD) or GST-PakRBD (GST-PAK PD). Bound proteins were analyzed by SDS-PAGE and immunoblotted with the indicated antibodies. (B-D) Signals obtained for GTP-RAP1, GTP-

CDC42, and GTP-RAC1 as shown in A were quantified using a fluorescence-based detection system. (E) WT and CRK/CRKL Dko CD4 ${ }^{+} T$ cells were cultured under Th1-skewing conditions and stimulated with $10 \mathrm{nM} \mathrm{CXCL10.} \mathrm{Activation} \mathrm{of} \mathrm{RAP1} \mathrm{was}$ assessed as in $\mathbf{A}$ and quantified in $\mathbf{F}$. Representative data from at least 3 experiments are shown. activated WT and CRK/CRKL Dko CD4 ${ }^{+}$T cells were stimulated
$\mathbf{E}$

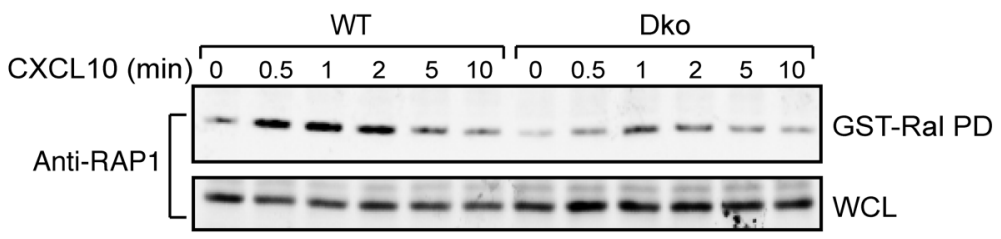

cells, CRK proteins act upstream of C3G and DOCK180 to regulate activation of the small GTPases RAP1 and RAC1, respectively (4). We therefore performed effector pull-down assays to assess GTPase activation. In WT T cells, RAC1-GTP levels increased within 0.5 minutes after chemokine addition and remained elevated for 2-5 minutes (Figure 5, A and D). The kinetics of RAC1 activation varied somewhat among experiments, precluding averaging of results. Nonetheless, CRK protein deficiency consistently failed to affect the magnitude or the kinetics of RAC1 activation. In contrast, RAP1 activation was attenuated in CRK/CRKL Dko T cells (Figure 5, A and B). Similar defects in RAP1 activation were observed in CRK/CRKL Dko Th1 cells stimulated with CXCL10 (Figure 5, E and F). Finally, although CRK proteins have not been previously implicated in activation of CDC42, we also observed blunting of CDC42 activation in CRK/CRKL Dko T cells (Figure 5, A and $\mathrm{C}$ ). Thus, we conclude that CRK proteins promote chemokineinduced activation of RAP1 and CDC42, but not RAC1.

$C R K$ and CRKL coordinate C3G and CASL to regulate $T$ cell diapedesis. Since RAP1 activation was defective in CRK/CRKL Dko $\mathrm{T}$ cells, we asked whether activation of the RAP1 GEF C3G was also perturbed. C3G was isolated from chemokine-stimulated WT and CRK/CRKL Dko T cells based on binding to recombinant CRKL-nSH3 (13), and tyrosine phosphorylation was assessed by immunoblotting. As shown in Figure 6B, phosphorylation of C3G was blunted in CXCL10-stimulated CRK/CRKL Dko T cells. Similar results were obtained after stimulation with CCL21 (data not shown). Parallel analysis was performed for CASL (CRK-associated substrate in lymphocytes), a critical regulator of T cell migration that interacts with the SH2 domain of CRK proteins (ref. 23 and Figure 6A). As shown in Figure 6C, tyrosine phosphorylation 

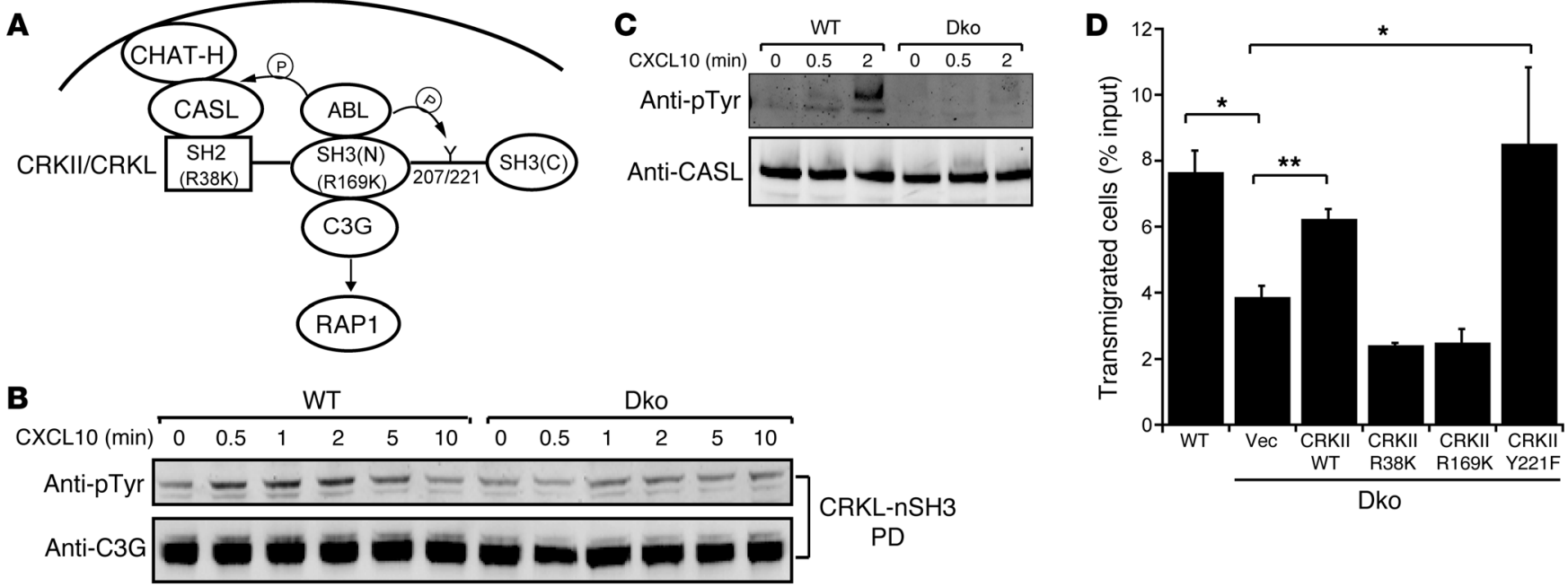

Figure 6. CRK and CRIKL interact with C3G and CASL to regulate T cell diapedesis. (A) Schematic drawing showing a proposed CHAT-H-CASL-CRK/CRKLC3C module that could regulate RAP1 activation in response to chemokine stimulation. CASL binds to the SH2 domains of CRK proteins, and mutation of the SH2 domain (CRKII R38K) interrupts this association. Both C3G and c-ABL bind to the $\mathrm{nSH} 3$ domains of CRK and CRKL, and mutation in the SH3 domain (CRKII R169K) interrupts these interactions. c-ABL phosphorylates CASL, CRKII at Y221, and CRKL at Y207. CHAT-H constitutively associates with CASL and recruits CASL to the plasma membrane. Chemokine stimulation induces CASL tyrosine phosphorylation by ABL family kinases and provides binding sites for the SH2 domains of CRK proteins. The association between CRK and CASL brings C3C to the membrane and activates RAP1. (B and C) Preactivated CD4+ $\mathrm{T}$ cells were stimulated with CXCL10 for the indicated times, lysed, and incubated with recombinant CRKL-SH3 protein to pull down C3C or immunoprecipitated with anti-CASL. The precipitants were blotted with the indicated antibodies. (D) CRK/CRKL Dko CD4 ${ }^{+}$T cells were reconstituted with the indicated CRKII mutants, and diapedesis was assessed. Data represent mean \pm SD of replicate samples from 1 experiment, representative of 4 independent experiments. ${ }^{*} P<0.05,{ }^{* *} P<0.01$. Statistical analysis was performed using a paired 2-tailed Student's $t$ test.

of CASL was almost completely abolished in Dko T cells, indicating that CRK proteins also promote CASL activation.

To further test the functional importance of CRK protein adaptor function, we made point mutations in the SH2 (R38K) or nSH3 (R169K) domain of CRKII to interrupt binding to CASL or C3G, respectively (24) (Figure 6A). WT or mutant CRKII proteins were expressed in Dko T cells, and diapedesis was analyzed. As shown in Figure 6D, diapedesis was rescued by reconstitution with WT CRKII but not with the R38K or the R169K mutants. In some settings, adaptor function of the CRKII SH2 and nSH3 domains is negatively regulated by phosphorylation at Y221; however, we found that a non-phosphorylatable CRKII Y221F mutant rescued $\mathrm{T}$ cell diapedesis no better than WT CRKII protein. Thus, either CRKII-dependent diapedesis is not repressed by phosphorylation or diapedesis is maximal and cannot be further upregulated under the conditions tested. Taken together, these studies show that adaptor function mediated by the $\mathrm{SH} 2$ and $\mathrm{nSH} 3$ domains of CRK proteins promotes activation of C3G and RAP1 as well as CASL, leading to enhanced $\mathrm{T}$ cell diapedesis.

$C R K$ and $C R K L$ are dispensable for $T$ cell homing but are required for migration to sites of inflammation. To test CRK protein function in vivo, we first analyzed homing to lymphoid organs. First, resting $\mathrm{CD}^{+} \mathrm{T}$ lymphoblasts prepared from WT or CRK/CRKL Dko mice were mixed and injected into recipient mice, and shortterm (1 hour) homing to lymphoid organs was assessed by flow cytometry. As shown in Figure 7A, the ratio of CRK/CRKL Dko to WT T cells was slightly less than 1 in lymph node and spleen and approximately 0.5 in blood. The reason for this diminished ratio is unclear and may reflect aberrant trapping of the mutant cells in non-hematopoietic tissues. Nonetheless, these data show that homing of CRK/CRKL Dko T cells to lymphoid organs is grossly normal. To circumvent the complexities associated with homing of resting $\mathrm{T}$ lymphoblasts, we also tested homing of naive $\mathrm{T}$ cells. Lymphocytes from CRK/CRKL Dko Rosa-EYFP (CD45.2 $)$ and B6.SJL (CD45.1 $\left.1^{+}\right)$mice were mixed 1:1 and adoptively transferred into WT recipient mice $\left(\mathrm{CD} 45.2^{+}\right)$. To control for the genetic background of CRK/CRKL Dko and SJL mice, we performed parallel experiments using fluorescently labeled cells from WT littermates $\left(\mathrm{CD} 45.2^{+}\right)$, mixed with cells from B6.SJL mice. As shown in Figure $7 \mathrm{~B}$, the homing efficiency of naive $\mathrm{CD} 4^{+} \mathrm{CRK} / \mathrm{CRKL}$ Dko $\mathrm{T}$ cells was virtually identical to that of WT T cells. This was also true for naive $\mathrm{CD} 8^{+} \mathrm{T}$ cells (data not shown).

Although we found that CRK proteins are not needed for homing to lymphoid organs, we reasoned that they might function in migration to inflamed tissues. To investigate this, we used a cutaneous delayed-type hypersensitivity model elicited by 2, 4-dinitrofluorobenzene (DNFB) to test Th1 entry into an inflamed site (25). Naive WT and CRK/CRKL Dko CD4 $4^{+} \mathrm{T}$ cells were skewed in vitro to become Th1 cells, and did so with equal efficiency (Figure 7C). WT and Dko Th1 cells were then fluorescently labeled, mixed, and transferred into DNFB-treated recipient mice. Trafficking of transferred cells was analyzed 24 hours later. Consistent with the homing experiments above, CRK/CRKL Dko Th1 cells migrated efficiently to lymphoid tissues. Interestingly, however, the mutant cells showed significantly reduced trafficking to inflamed skin (Figure 7D). Thus, we conclude that CRK proteins preferentially promote $\mathrm{T}$ cell migration to sites of inflammation in vivo.

CRK/CRKL Dko T cells attenuate GVHD while preserving donor $T$ cell-mediated GVL effects. Since CRK proteins were important for migration into inflamed tissues, we reasoned that $\mathrm{T}$ cells lacking 
A
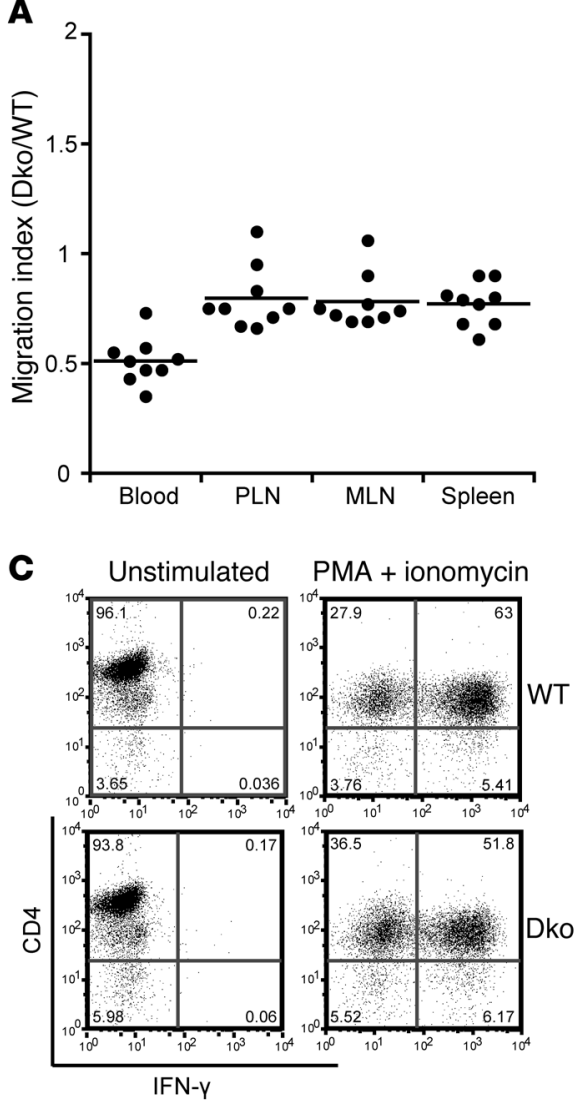

B

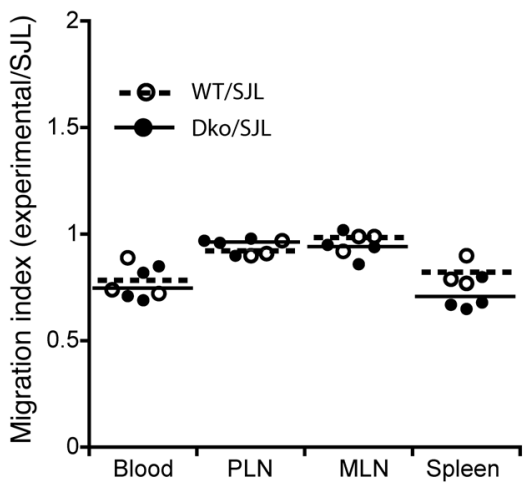

D

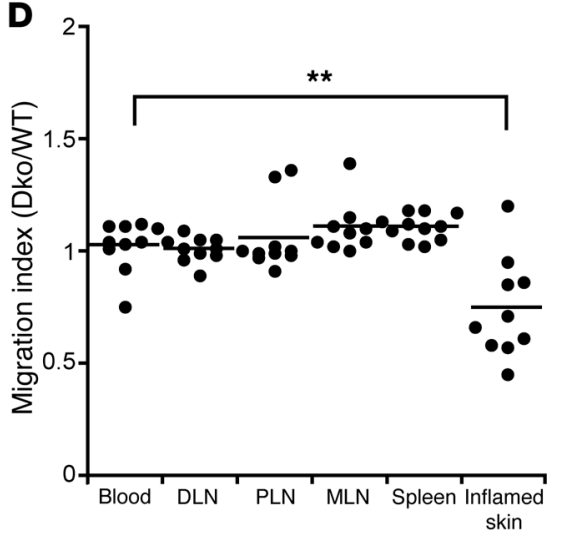

Figure 7. CRK/CRKL-deficient T cells have defects in migration to inflamed skin. (A) Resting WT or Dko CD4 ${ }^{+}$T lymphoblasts were labeled with CFSE or CMTMR, mixed, and injected into recipient mice. One hour after injection, cells were collected from blood, peripheral lymph nodes (PLN), mesenteric lymph nodes (MLN), and spleen, and the ratio of Dko to WT T cells was determined. Pooled data from 3 experiments is shown ( $n=9$ total mice). (B) PLN lymphocytes from WT mice (CD45.2+) were labeled with CFSE, mixed with PLN Iymphocytes from B6.SJL mice (CD45.1 ), and injected i.v. into recipient mice. In parallel, PLN lymphocytes from CRK/CRKL Dko Rosa-YFP mice (CD45.2+) were mixed with PLN lymphocytes from B6.SJL mice (CD45.1 $1^{+}$and injected into recipient mice (CD45.2+). Cells were harvested from blood, PLN, MLN, and spleen 1 hour after transfer, and the ratio of naive (CD62 $\left.\mathrm{L}^{\text {hi }}, C D 44^{10}\right)$ experimental (CFSE ${ }^{+}$WT or EYFP+ Dko) to competitor (CD45.1 $\left.1^{+}\right) \mathrm{CD}^{+}+$cells in the recovered populations was determined and normalized to the input ratio. Data represent individual mice from 1 experiment ( $n=7$ total mice). (C) CD4 ${ }^{+}$T cells were purified from WT and Dko mice, and Th1 cells were cultured in vitro. Percentages of WT and Dko Th1 cells were analyzed by intracellular flow. (D) Skin inflammation was induced in recipient mice using DNFB as described in Methods. WT and Dko Th1 cells cultured as in C were stained with CFSE or CMTMR, mixed 1:1, and injected intravenously into recipient mice. Twenty-four hours after injection, blood, draining lymph nodes (DLN), PLN, MLN, spleen, control skin, and inflamed skin were collected, and adoptively transferred cells were analyzed by flow cytometry. Combined data from 3 experiments $\left(n=10\right.$ total mice) are shown. ${ }^{* *} P<0.01$. Statistical analysis was performed using a paired 2-tailed Student's $t$ test.

these proteins would exhibit attenuated GVHD. To test this, we performed allogeneic BM transplantation $(\mathrm{B} 6 \rightarrow \mathrm{BALB} / \mathrm{c})$ with WT or CRK/CRKL Dko CD4 ${ }^{+} \mathrm{T}$ cells. Compared with mice receiving $\mathrm{BM}$ alone, BM-transplanted mice receiving WT T cells exhibited severe GVHD, characterized by continued weight loss and mortality within 30 days after transplantation (Figure $8, \mathrm{~A}-\mathrm{C}$ ). In contrast, BM-transplanted mice receiving CRK/CRKL Dko T cells exhibited modest GVHD and weight loss, with $70 \%$ of mice surviving until the end of the experiment. These results indicate that CRK proteins play a critical role in GVHD pathogenesis.

Although allogeneic T cells cause unwanted GVHD, they also mediate beneficial effects by eradicating residual leukemia cells, a process known as the GVL effect. Thus, devising ways to separate GVHD and GVL responses is critical for improving allogeneic BM transplant outcomes. One potential strategy involves retaining allogeneic $\mathrm{T}$ cells in lymphoid organs where leukemic cells reside, allowing GVL but not GVHD effects to occur (26). Based upon the differential migration of CRK/CRKL Dko T cells, we hypothesized that these cells might display intact GVL responses with reduced GVHD. To test this, we injected allogeneic BM-transplanted mice with or without purified WT or CRK/CRKL Dko CD8 ${ }^{+} \mathrm{T}$ cells and challenged them with host-type A20 lymphoma cells. BM-transplanted mice receiving lymphoma cells without any $\mathrm{T}$ cells exhibited rapid tumor growth and succumbed to the tumor within 2-3 weeks (Figure 8, D-G). BM-transplanted mice receiving WT $\mathrm{T}$ cells controlled tumor growth but died from GVHD within 30 days. In contrast, BM-transplanted mice receiving CRK/CRKL Dko T cells exhibited an equally potent GVL effect, but with significantly attenuated GVHD. Indeed, all recipients of CRK protein-deficient $\mathrm{T}$ cells survived to the end of the experiment. These results indicate that $\mathrm{T}$ cells that lacking CRK proteins can control GVHD while preserving beneficial GVL, leading to significantly improved survival of allogeneic BM transplant recipients.

Finally, to ask whether the ability of CRK/CRKL Dko T cells to carry out GVL with minimal GVHD is related to their differential migratory capacity, we analyzed $\mathrm{T}$ cell trafficking in the GVHD model using a competitive assay. $\mathrm{CD} 8^{+}$ $\mathrm{T}$ cells purified from WT or CRK/CRKL Dko mice were mixed with competitor $\mathrm{T}$ cells from WT B6.SJL mice and injected together with $\mathrm{T}$ cell-depleted BM into allogeneic recipient mice. Ten to 12 days later, the ratios of adoptively transferred WT or Dko CD8 ${ }^{+} \mathrm{T}$ cells to competitor $\mathrm{CD} 8^{+}$ $\mathrm{T}$ cells were compared in spleen and liver. As shown in Figure $8 \mathrm{H}, \mathrm{WT}$ and competitor T cells migrated to liver and spleen with similar efficiency, with a ratio near 1 in both tissues. Dko $\mathrm{T}$ and competitor $\mathrm{T}$ cells also migrated with similar efficiency to spleen, consistent with the results in Figure 7. In contrast to WT T cells, however, the Dko $\mathrm{T}$ cells showed a significant competitive disadvantage in trafficking to liver, a key GVHD target organ. Thus, the attenuated GVHD response we observe in mice transplanted with CRK/CRKL Dko T cells was at least partially attributable to defects in T cell trafficking into GVHD target organs. 

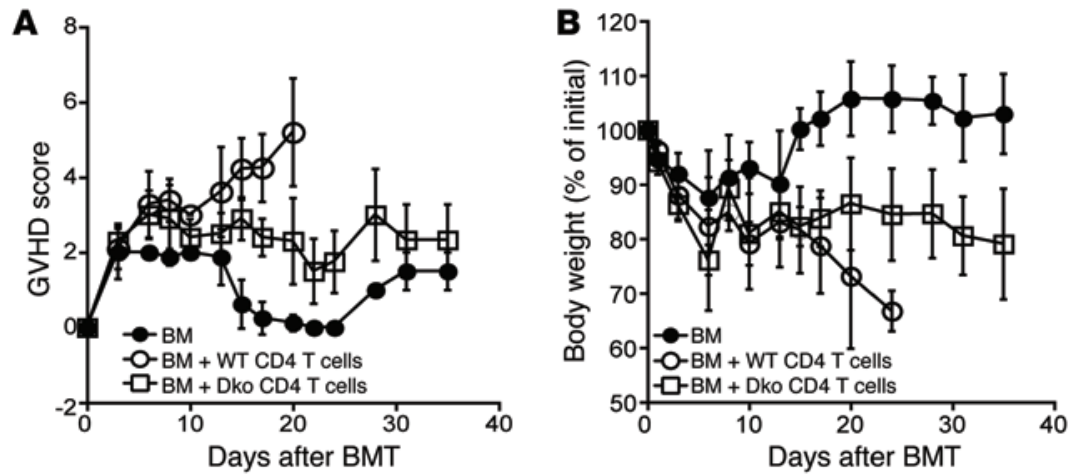

C
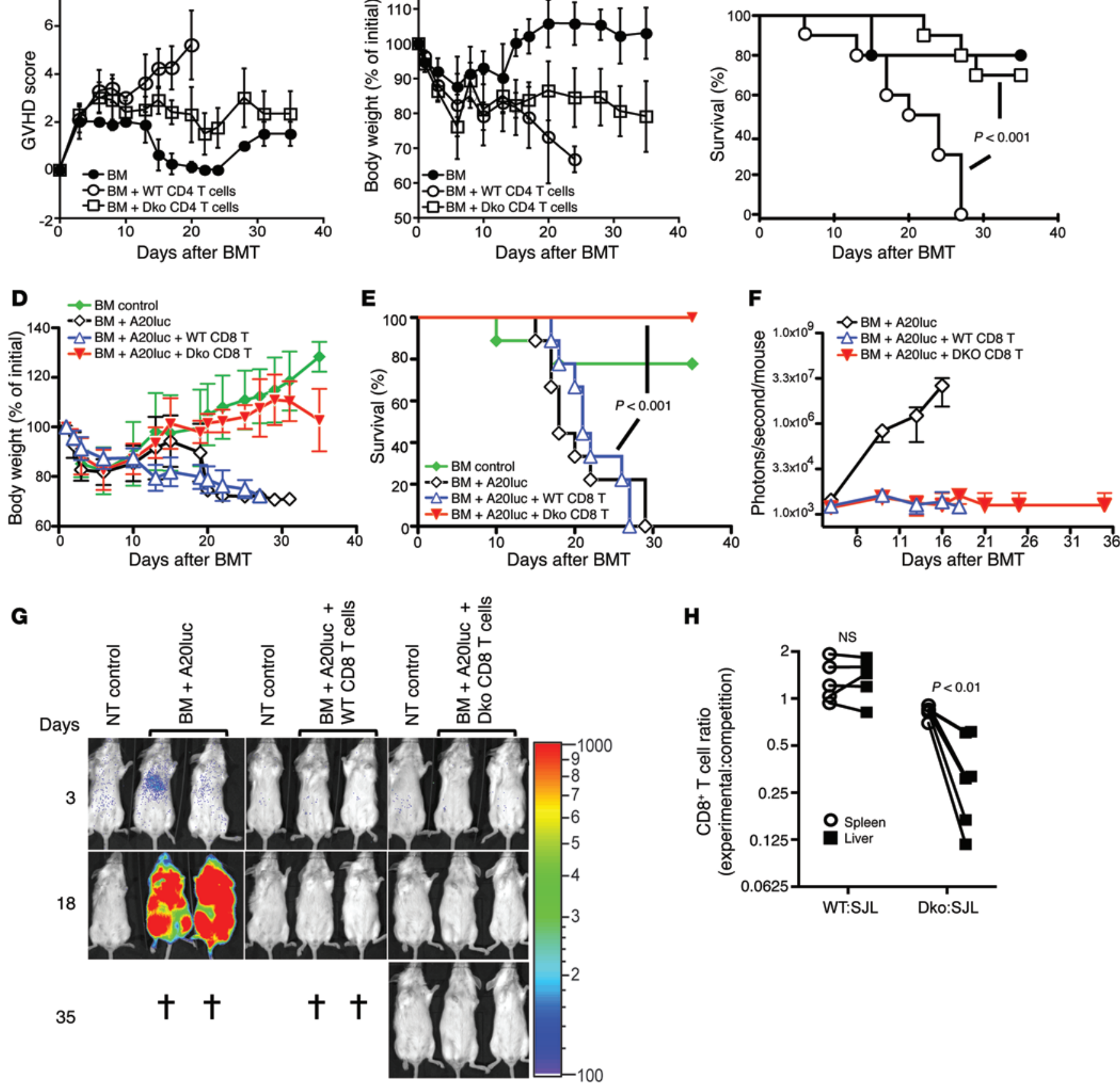

Figure 8. CRIK/CRKL Dko donor T cells can carry out GVL with minimal GVHD. (A-C) T cell-depleted bone marrow cells alone (BM, H-2b), mixed with purified WT CD4 ${ }^{+}$T cells (BM + WT CD4 T cells, $\mathrm{H}-2 \mathrm{~b}$ ), or mixed with purified CRK/CRKL Dko CD4 ${ }^{+} \mathrm{T}$ cells (BM + Dko CD4 T cells, $\left.\mathrm{H}-2 \mathrm{~b}\right)$ were injected into lethally irradiated BALB/c hosts ( $\mathrm{H}-2 \mathrm{~d})$. Host GVHD clinical scores (A), body weight change (B), and survival (C) are summarized. Combined data from 2 different experiments are shown, with a total of 5-10 mice for each experimental group. (D-C) Lethally irradiated BALB/c hosts were injected with T cell-depleted bone marrow cells alone (BM control), or together with luciferase-transduced A20 cells (BM + A2Oluc), purified WT CD8+ T cells (BM + A2Oluc + WT CD8 T), or CRK/CRKL Dko CD8+ T cells (BM + A2Oluc + Dko CD8 T). Host body weight change (D), survival (E), and tumor burden (reflected by the luciferase signal) ( $\mathbf{F}$ and $\mathbf{G}$ ) are summarized. E shows combined data from 2 different experiments, with a total of 8-10 mice per experimental group. $\mathbf{D}$ and $\mathbf{F}$ show data from 1 of 2 independent experiments, with 5 mice for each experimental group. (H) To assess T cell migration during GVHD, congenically marked CD8 ${ }^{+} T$ cells from WT or CRK/CRKL Dko mice were mixed 1:1 with competitor SJL T cells (all H-2b) and injected together with T cell-depleted bone marrow cells into lethally irradiated BALB/c host mice (H-2d). Spleen and liver were harvested after 10-12 days, and the ratio of experimental (WT or Dko) to competitor adoptively transferred cells was determined. Paired data (combined from 2 experiments) are shown, with a total of 5 (WT) or 6 (Dko) recipient mice. Error bars represent mean $\pm \mathrm{SD}$. Statistical analysis in $\mathbf{C}, \mathbf{E}$, and $\mathbf{H}$ was performed using a 1-way ANOVA. 


\section{Discussion}

In this article, we show what we believe to be a novel role for CRK proteins in regulating chemokine-dependent adhesion, migration, and diapedesis of $\mathrm{T}$ cells, and we place these molecules in the signaling pathway linking chemokine receptor engagement to integrin activation. Surprisingly, we found that T cells lacking CRK proteins maintain effector function and the ability to home to lymphoid organs, but show selective defects in migration into inflamed tissues. This phenotype has important therapeutic implications, since T cells lacking CRK proteins can carry out effective GVL responses while eliciting minimal GVHD-associated morbidity and mortality.

At the molecular level, we show that CRK proteins function to promote chemokine-dependent integrin activation by RAP1, a key event needed for adhesion to endothelial cells and subsequent diapedesis (27). Previous work has shown that CRK proteins signal through the RAP1 GEF C3G to regulate RAP1 activation $(4,13,14$, 28). We now show that this pathway is important for chemokineinduced $\mathrm{T}$ cell adhesion and migration. In other systems, CRKdependent activation of $\mathrm{C} 3 \mathrm{G}$ involves both recruitment of $\mathrm{C} 3 \mathrm{G}$ to the cell membrane and phosphorylation at Tyr504 (29, 30). Consistent with this, chemokine-stimulated C3G phosphorylation was reduced in CRK protein-deficient $\mathrm{T}$ cells. It remains to be determined whether C3G localization is also affected. We observed that in addition to playing a role in inside-out signaling pathways leading to integrin activation, CRK/CRKL Dko T cells polarized poorly in response to fibronectin ligation. This indicates that these proteins, like RAP1 $(27,31)$, are also required for outside-in integrin signaling.

Our work also sheds new light on the relevant upstream signaling events. CHAT-H (CAS and HEF-1-associated signal transducer in hematopoietic cells) constitutively binds to CASL (32), localizing the complex to the plasma membrane. Work by Regelman et al. has shown that chemokine stimulation triggers CASL phosphorylation and recruits an unknown signaling intermediate to CHAT-H-CASL modules, leading to RAP1 activation (33). Since CASL binds the SH2 domains of CRK proteins (23), and mediates their localization to the plasma membrane $(5,34)$, we reasoned that CRK proteins might be the missing intermediate in this complex. In support of this idea, we now show that interaction of CASL and C3G with CRKII is required for CRK's function in regulating $\mathrm{T}$ cell diapedesis. Thus, we propose a unified model through which a CHAT-H-CASL-CRK/CRKL-C3G complex controls local RAP1 activation in migrating $\mathrm{T}$ cells (Figure 6A).

In addition to regulating RAP1, CRK proteins can activate RAC1 by signaling through DOCK180 (4). Surprisingly, however, we found that RAC1 activation was intact in CRK/CRKL Dko T cells. Peripheral blood leukocytes express DOCK2 rather than DOCK180 (35), and the connection between DOCK2 and CRK proteins is debated $(35,36)$. In support of the view that CRK proteins do not signal through DOCK2 in this system, the phenotypes of DOCK2 and CRK/CRKL-deficient T cells are very different. In Dock2 ${ }^{--} \mathrm{T}$ cells, chemokine-induced RAC1 activation and actin polymerization are almost entirely abolished (37), while adhesion and transendothelial migration are fairly normal $(38,39)$. In contrast, we found that CRK/CRKL-deficient T cells exhibit clear defects in adhesion and diapedesis, with more modest defects in migration. Indeed, migration in a 3D environment, a process that depends on RAC1-driven actin polymerization but not on integrins
(22), was normal. Although RAC1 activation was intact, activation of CDC42 was reduced in CRK/CRKL Dko T cells. This is an important finding, since CDC42 activity promotes T cell crawling along endothelial cells and probing for suitable sites for transendothelial migration (40). Evidently, the residual levels of CDC42 activation are sufficient to support directional T cell migration in the $3 \mathrm{D}$ collagen gel assay. Nonetheless, defects in CDC42 activity likely contribute to the diapedesis defects we observed. How CRK proteins regulate $\mathrm{CDC} 42$ is unclear. CDC42 may be activated downstream of RAP1 (31), or other DOCK family proteins may be involved.

Since CRK proteins are best known as substrates for ABL family kinases, it is important to consider how ABL kinases fit into the pathways we have defined. Phenotypically, there are similarities and differences between CRK-deficient and ABL-deficient $\mathrm{T}$ cells. We reported previously that $\mathrm{T}$ cells lacking c-ABL show chemotactic defects in Transwell assays (41); however, these cells do not exhibit defective diapedesis (Y. Huang, unpublished observations). In vivo studies by $\mathrm{Gu}$ et al. (42) showed that T cells lacking ABL and ARG have defects in migration to lymphoid organs as well as to sites of inflammation. Thus, they lack the selective trafficking defects described here. Since ABL kinases typically negatively regulate CRK proteins (7), it seems paradoxical that loss of either ABL kinases or CRK adaptors impairs migration. Moreover, we found that mutating the ABL phosphorylation site in CRKII had no effect on diapedesis. The simplest explanation for this is that $\mathrm{ABL}$ kinases do not regulate diapedesis by phosphorylating CRK proteins at their inhibitory sites. Instead, we favor the idea that CRK proteins bring ABL kinases in proximity with other substrates. Gu et al. have shown that ABL kinases can phosphorylate CASL (HEF-1) and activate RAP1 in response to chemokine stimulation, thereby promoting $\mathrm{T}$ cell migration (42). As diagrammed in Figure 6A, binding of ABL kinases to CRK proteins could provide a feedback loop to facilitate CASL tyrosine phosphorylation. This likely explains our finding that in CRK/CRKL Dko T cells, CASL tyrosine phosphorylation is almost completely abolished.

Another important question is the extent to which CRK isoforms have unique versus overlapping functions. The $\mathrm{SH} 2$ and SH3 domains of CRKII and CRKL are highly conserved, their interaction specificities are almost identical, and redundancy has been reported in other pathways $(14,43,44)$. However, there is also evidence for unique functions, since mice singly deficient for either CRK or CRKL exhibit severe developmental defects (10, 11). In T cells, we found that deletion of either gene alone led to defective diapedesis, with loss of CRKL expression being particularly deleterious. Two possibilities are consistent with this finding: either CRK proteins cannot fully compensate for one another, or the overall expression level of all CRK isoforms is important. In support of the latter idea, we found that overexpression of any CRK isoform in doubly deficient cells could restore normal function. Thus, we conclude that CRKI, CRKII, and CRKL play partially overlapping roles in $\mathrm{T}$ cell adhesion and migration.

One of the most striking outcomes of this study is that although CRK/CRKL-deficient T cells can home to lymphoid organs, they show impaired transmigration across a TNF- $\alpha$-activated endothelium and migrate poorly to sites of inflammation. Additional study will be needed to pinpoint the basis for this differential migratory capacity. It cannot be attributed to chemokine receptor 
signaling, since CRK/CRKL Dko T cells responded similarly to homing (CCL21, CXCL12) and inflammatory (CXCL10) chemokines. Differences in naive versus previously activated $\mathrm{T}$ cells are also unlikely, since effector Th1 cells reached lymphoid organs efficiently. The most attractive possibility is that CRK proteins are required for passage across postcapillary venules, but not for crossing HEVs. T cell integrins mediate firm adhesion to the endothelial wall and trigger signaling events within the endothelial cells that induce junctional weakening and promote $\mathrm{T}$ cell passage $(45$, 46). Thus, defective integrin activation in CRK/CRKL-deficient $\mathrm{T}$ cells could fail to trigger the appropriate endothelial response. The differences between postcapillary venules and HEVs are not fully understood, but it is clear that HEVs are highly specialized to regulate lymphocyte passage (47). In particular, HEV junctional complexes are more permeable, and they produce factors that trigger distinct $\mathrm{T}$ cell signaling events $(48,49)$. These HEV specializations may therefore circumvent the need for CRK protein signaling.

In many respects, the migration defects we observe in the immune system parallel defects in neuronal migration in the developing mouse cortex. Migrating neurons lacking both CRK and CRKL fail to pass through cortical preplate cells and earlierborn neurons, resulting in disruption, and apparent inversion, of cortical layers (14). As in T cell migration, the CRK/CRKL-C3GRAP1 pathway is considered to play critical roles in Reelin-dependent neuronal migration. Therefore, it is possible that CRK and CRKL function to modulate the cell-cell interactions that allow migrating cells to pass through nonmigrating cell boundaries. It will be interesting to test the generality of this idea.

The differential migratory behavior of CRK-deficient $\mathrm{T}$ cells has important ramifications, since these cells can elicit strong GVL responses (which take place largely in lymphoid tissues) with minimal GVHD. Mice lacking CD18 or CCR7 also exhibit effective GVL activity associated with absent or attenuated GVHD responses (50, 51), as do mice lacking PKC $\theta$ (52). While these models are superficially similar, closer examination reveals important differences. For example, $C c 7^{---}$T cells show defects in trafficking to recipient lymph nodes, while $\mathrm{Cd} 18^{--} \mathrm{T}$ cells migrate efficiently to lymph nodes but are defective in their ability to enter inflamed skin and GVHD target tissues such as intestine $(50,53)$. PKC $\theta$ deficiency was shown to affect GVHD via altered $\mathrm{T}$ cell effector function (52), but trafficking may also be affected, since PKC $\theta$ is known to regulate RAP1 activation and $\mathrm{T}$ cell trafficking in other settings $(16,54)$. CRK-deficient $\mathrm{T}$ cells, which migrate efficiently to lymphoid organs but inefficiently to liver in a GVHD model, most closely resemble the $C d 18^{-/-} \mathrm{T}$ cells. Additional kinetic analysis of $\mathrm{T}$ cell trafficking and target organ damage will be needed to fully understand how CRK protein deficiency affects the balance between GVL and GVHD. Unlike CD18or CCR7-deficient T cells, T cells lacking CRK proteins retain partial chemokine sensing and integrin function. Thus, trafficking of these cells may be uniquely dependent on density of integrin ligands, presence or absence of shear flow, and other tissue-specific variables.

In the GVL/GVHD model, CRK/CRKL Dko CD8 ${ }^{+}$T cells eliminated tumor cells as efficiently as WT cells, indicating that in vivo effector function was intact. This was somewhat surprising, since CRK proteins have previously been implicated in TCR signaling $(13,28)$, and since we observed decreased adhesion in response to anti-TCR stimulation in CRK/CRKL-deficient T cells (Figure
2A). In preliminary studies, we did not observe defects in $\mathrm{T}$ cell activation or proliferation (data not shown), but the strong stimuli we used (anti-TCR or superantigen in vitro, alloantigen in vivo) may mask a role for CRK family proteins. In future studies, it will be important to ask whether CRK proteins promote LFA-1-mediated costimulation and/or memory responses to cognate peptidemajor histocompatibility complexes.

Our findings identify CRK proteins as highly promising therapeutic targets for disrupting deleterious $\mathrm{T}$ cell trafficking to inflamed tissues, including GVHD target organs. Related strategies based on blocking integrins or chemokine receptors have shown promise in chronic inflammatory diseases such as inflammatory bowel disease and multiple sclerosis $(55,56)$, as well as GVHD (26), but because the initiation and end points of the signaling cascade are targeted, multiple facets of the immune response are compromised. As intermediates in the pathway, CRK and CRKL may be valuable targets with more confined effects. In particular, targeting CRK proteins in human donor $\mathrm{T}$ cells could reduce morbidity while maintaining efficient GVL responses in allogeneic hematopoietic stem cell transplant recipients.

\section{Methods}

Mice. Mice homozygous for both floxed Crk and Crkl genes (14) were crossed with Cd4-Cre transgenic (Tg) mice on the C57BL/6 background (Taconic) to generate mice with deletion of Crk and Crkl late in $\mathrm{T}$ cell development. Some of these mice were further crossed to Rosa26-YFP mice (The Jackson Laboratory) to monitor Cre expression (15). WT littermates were used as controls. BALB/c and B6/SJL mice were obtained from The Jackson Laboratory.

Cell isolation and culture. Naive $\mathrm{CD} 4^{+} \mathrm{T}$ cells were purified from lymph nodes and/or spleen by negative selection as previously described (41). To generate preactivated T cells, freshly isolated CD $4^{+}$ $\mathrm{T}$ cells were stimulated in 24 -well plates coated with $1 \mu \mathrm{g} / \mathrm{ml}$ anti-CD3 (2C11, BioXCell) and anti-CD28 (PV-1, BioXCell) at $37^{\circ} \mathrm{C}$. Two days after stimulation, $\mathrm{T}$ cells were split into fresh non-stimulating wells and cultured for an additional 4-7 days. Experiments were performed 4-6 days after removal from anti-CD3/anti-CD28. Th1 cells were generated as previously described (25). Briefly, $\mathrm{CD}^{+}{ }^{+} \mathrm{T}$ cells were seeded on anti-CD3- and anti-CD28-coated plates and cultured in the presence of $20 \mathrm{ng} / \mathrm{ml} \mathrm{IFN}-\gamma$ (eBioscience), $5 \mathrm{ng} / \mathrm{ml} \mathrm{IL-12} \mathrm{(R \& D} \mathrm{Systems),}$ and $1 \mu \mathrm{g} / \mathrm{ml}$ anti-IL-4 (Biological Resource Branch, National Cancer Institute, Frederick, Maryland, USA) for 3 days. Cells were then transferred to new plates and supplemented with the same concentrations of cytokines and $25 \mathrm{IU} / \mathrm{ml}$ rhIL-2 (obtained through the AIDS Research and Reference Reagent Program, Division of AIDS, NIAID, NIH; rhIL-2 from Maurice Gately, Hoffmann-La Roche Inc.).

Retroviral transduction. cDNAs encoding CRKI, CRKII, CRKL, CRKII R38K, CRKII R169K, or CRKII Y221F were cloned into MigR1, which co-expresses eGFP from a bicistronic message, and production of high-titer retroviral supernatant in 293T cells was done as previously described (57). Primary CD4 $4^{+} \mathrm{T}$ cells were transduced after 2 days of plate-bound anti-CD3 and anti-CD28 stimulation. Cells were collected and re-seeded as $2.5 \times 10^{5} /$ well in 24 -well plates, and spin infected with freshly prepared retroviral supernatants, containing $2 \mu \mathrm{g} / \mathrm{ml}$ Polybrene (Sigma-Aldrich) at $850 \mathrm{~g}$ for 90 minutes at $25^{\circ} \mathrm{C}$. After the spin infection, cells were washed and cultured with $100 \mathrm{IU} / \mathrm{ml} \mathrm{IL}-2$ for an additional 5 days in the absence of stimulation. 
Reagents, antibodies, and flow cytometry. All reagents were from Sigma-Aldrich unless otherwise specified. Antibodies against CRK, RAP1, and RAC1 were from BD Biosciences. Anti-phospho-ERK p42/p46 was from Cell Signaling Technology Inc. Anti-CRKL (C-20) was from Santa Cruz Biotechnology. Anti-ZAP70 has been described previously (58).

For flow cytometry, single-cell suspensions were stained with the following fluorescently conjugated antibodies from BioLegend: B220 (RA3-6B2), CD25 (PC61), CD29 (HM_1-1), CD4 (RM4-5), CD44 (IM7), CD45.1 (A20), CD62L (MEL-14), CD69 (H1.2F3), CD8 (53-6.7), and CXCR3 (CXCR3-173) or with CD11a (I21/7, BD Biosciences). Intracellular labeling with mouse anti-CRK, followed by PE-conjugated anti-mouse IgG (BioLegend), and rabbit anti-CRKL, followed by Alexa Fluor 488-conjugated anti-rabbit IgG (Invitrogen), or allophycocyaninconjugated IFN- $\gamma$ (XMG1.2, eBioscience) was performed as previously described (59). For intracellular labeling of IFN- $\gamma$, T cells were stimulated with PMA (50 ng/ml) and ionomycin $(500 \mathrm{ng} / \mathrm{ml})$ for 4 hours. Two hours prior to harvest, brefeldin A $(1 \mu \mathrm{g} / \mathrm{ml})$ was added to the cells. Cells were analyzed by flow cytometry using a FACSCalibur or LSR II (BD Biosciences). Analysis was carried out using FlowJo (Tree Star).

To detect CCR7 surface expression, cells were incubated with mouse CCL19-Fc (eBioscience) for 30 minutes at $4^{\circ} \mathrm{C}$, washed, and incubated with biotin-conjugated anti-human IgG (Fc fragment specific, Jackson ImmunoResearch Laboratories) for 20 minutes. Cells were washed again, stained with PE-conjugated streptavidin (eBioscience), and analyzed by flow cytometry.

RAP1, CDC42, and RAC1 pull-down assay and C3G and CASL immunoprecipitation. T cells were stimulated with $10 \mathrm{nM} \mathrm{CCL} 21$ or CXCL12, lysed, and subjected to GST-RalGDS (for RAP1) or GSTPakRBD (for RAC1 and CDC42) precipitation as previously described (41). $1 \times 10^{7} \mathrm{~T}$ cell blasts per condition were used for each RAP1/CDC42 assay, and $5 \times 10^{6}$ cells per condition were used for each RAC1 assay. C3G immunoprecipitation was performed as previously described (13). Briefly, cells were chemokine stimulated, and lysates were incubated with GST-CRKL-nSH3 recombinant protein (from Daniel Billadeau, Mayo Clinic, Rochester, Minnesota, USA), followed by incubation with glutathione agarose resin (Thermo Scientific). For CASL immunoprecipitation, chemokine-activated cell lysates were incubated with anti-CASL (2G9, Abcam). The precipitants were immunoblotted for phospho-tyrosine (4G10, Millipore).

Adhesion and chemotaxis assay. Adhesion assays were performed as previously described (58) with some modifications. Ninety-six-well plates were coated with various doses of integrin ligands at $4^{\circ} \mathrm{C}$ overnight, then blocked with $2.5 \%$ BSA at room temperature for 1 hour. For ICAM-1, 96-well plates (Nunc MaxiSorp plate, Thermo Scientific) were coated with $100 \mu \mathrm{l}$ of $0.5 \mu \mathrm{g} / \mathrm{ml}$ or $1 \mu \mathrm{g} / \mathrm{ml}$ recombinant mouse ICAM-1 (R\&D Systems) per well. For fibronectin, 96-well plates (Costar plate 3596) were coated with $100 \mu \mathrm{l}$ of 3 or $10 \mu \mathrm{g} / \mathrm{ml}$ human fibronectin (R\&D Systems) per well. T cells were labeled with $2.5 \mu \mathrm{g} / \mathrm{ml}$ Calcein-AM (Invitrogen) at $37^{\circ} \mathrm{C}$ for 30 minutes, washed, and resuspended at $2 \times 10^{6} / \mathrm{ml}$ in PBS containing 2.5\% BSA, $\mathrm{Ca}^{2+}$, and $\mathrm{Mg}^{2+}$. Fifty microliters of cells were added to each well and left to settle for 20 minutes on ice, followed by the addition of $10 \mathrm{nM}$ chemokine, $1 \mu \mathrm{g} / \mathrm{ml}$ anti-CD3 (500A2, BD Biosciences), or $10 \mathrm{ng} / \mathrm{ml}$ PMA. Cells were warmed in a $37^{\circ} \mathrm{C}$ water bath for 10 minutes. The unbound cells were washed off, and adherent cells were measured using a Synergy HT Multi-Mode microplate reader (Biotek). The percentage of $\mathrm{T}$ cell adhesion was calculated as fluorescence of adherent cells/total fluorescence of cells added to each microplate well.
Chemotaxis assays were performed as previously described (41). Ninety-six-well ChemoTx chambers $(3-\mu \mathrm{m}$ pore size, Neuroprobe) were filled with buffer with or without $10 \mathrm{nM}$ chemokines in the bottom wells, and cells were applied to the upper wells. After 2 hours incubation at $37^{\circ} \mathrm{C}$, migrated cells collected from the bottom wells were quantified by flow cytometry.

$T$ cell polarization on fibronectin. Coverslips were acid washed by incubating in $10 \% \mathrm{H}_{2} \mathrm{O}_{2}$ in $0.1 \mathrm{~N} \mathrm{HCl}$ and then coated with $50 \mu \mathrm{g} / \mathrm{ml}$ fibronectin in PBS (containing $\mathrm{Mg}^{2+}$ and $\mathrm{Ca}^{2+}$ ) for 2 hours at room temperature. $5 \times 10^{4}$ preactivated $\mathrm{CD}^{+} \mathrm{T}$ cells made from WT or CRK/ CRKL Dko mice were added to each coverslip and allowed to adhere for 30 minutes at $37^{\circ} \mathrm{C}$. Cells were then fixed using 3\% PFA in PBS. In each experiment, at least $50 \mathrm{~T}$ cells of each genotype were blindly scored based on whether they were unpolarized (circular cells) or polarized (cells with an obvious leading edge and uropod).

Diapedesis assay. $4 \times 10^{5} 3 \mathrm{~B}-11$ endothelial cells (ATCC) were plated onto 35 -mm plastic ibiTreat $\mu$-dishes (ibidi) in DMEM with $10 \%$ FBS and incubated at $37^{\circ} \mathrm{C}$ overnight. Media was then replaced with DMEM containing $0.25 \%$ FBS. After 8-10 hours, some dishes were treated with $50 \mathrm{ng} / \mathrm{ml}$ TNF- $\alpha$ (PeproTech) to induce VCAM-1 and ICAM-1 upregulation. $2 \times 10^{5} \mathrm{WT}$ or CRK/CRKL Dko preactivated CD4 ${ }^{+} \mathrm{T}$ cells were added to the 3B-11 monolayers. In some experiments, WT and CRK/CRKL Dko T cells were stained with $2 \mu \mathrm{M}$ CFSE or $10 \mu \mathrm{M}$ CellTracker Orange CMTMR (both from Invitrogen) the day before imaging. Fluorescently labeled WT and CRK/CRKL Dko T cells were mixed 1:1 and added to the 3B-11 monolayers. Cells were maintained at $37^{\circ} \mathrm{C}$ during imaging. Images were collected every 30 seconds for 2 hours on an Axiovert 200M microscope (Zeiss) using a $\times 20$ LR objective and a Coolsnap FX-HQ camera (Roper Scientific). The T cells that underwent transendothelial migration were tracked and determined as percentage of total analyzed $\mathrm{T}$ cells.

As an alternative diapedesis assay, Transwell plate (Costar 3421) inserts were coated with $0.1 \%$ gelatin, and $3 \mathrm{~B}-11$ cells were grown on the insert overnight. The next day, 3B-11 cells were treated with 10-50 $\mathrm{ng} / \mathrm{ml} \mathrm{TNF-} \alpha$ for $12-16$ hours. T cells were then added to the insert, and 2 hours later, $\mathrm{T}$ cells that migrated through the inserts were collected and analyzed by flow cytometry.

$3 \mathrm{D}$ chemotaxis. 3D chemotaxis was performed using tissue culture-treated $\mu$-slide chemotaxis 3D chambers (ibidi). To produce collagen gels for migration studies, bovine skin collagen type I (PureCol, Advanced BioMatrix) was used at $1.6 \mathrm{mg} / \mathrm{ml}$ to make $5-\mu \mathrm{m}$-size pores (60). The collagen solution was neutralized and mixed with $\mathrm{T}$ cell blasts according to the manufacturer's instructions, to yield a final concentration of $1 \times$ DMEM, $1.2 \% \mathrm{FBS}, 0.3 \% \mathrm{NaHCO}_{3}$, and $1.6 \times 10^{6}$ $\mathrm{T}$ cells/ml. The collagen-cell suspension was loaded into the chambers and allowed to polymerize at $37^{\circ} \mathrm{C}, 5 \% \mathrm{CO}_{2}$ for 1 hour. $80 \mathrm{nM} \mathrm{CCL19}$ or CCL21 in DMEM containing 1\% FBS was added to one reservoir of each chamber, and DMEM containing $1 \%$ FBS was added to the opposite reservoir. Chambers were incubated for 30 minutes at $37^{\circ} \mathrm{C}$ to allow establishment of a linear chemokine gradient. Multiple chemotaxis chambers were visualized in parallel using a $\times 5$ objective on a Zeiss Axiovert $200 \mathrm{M}$ inverted microscope equipped with an automated stage and a $37^{\circ} \mathrm{C}$ environmental chamber. Images were collected at 1-minute intervals for 4 hours, using Slidebook 5.0 (Intelligent Imaging Innovations). Analysis was performed using the ibidi chemotaxis plugin for ImageJ, as described in ref. 61. Analysis was restricted to motile $\mathrm{T}$ cells by eliminating objects that were present in the field of 
view for less than 30 minutes and that displaced less than $15 \mu \mathrm{m}$. Population analysis of unfiltered data did not reveal significant differences in the proportion of motile T cells in WT and CRK/CRKL Dko samples.

In vivo migration assays. For $\mathrm{T}$ cell homing, purified $\mathrm{CD} 4^{+} \mathrm{T}$ cells from WT or CRK/CRKL Dko mice were activated with anti-CD3 and anti-CD28 for 3 days and rested for 4 days. These rested $\mathrm{T}$ cells were stained with CFSE or CMTMR and mixed 1:1, and a total of $1 \times 10^{7}$ to $2 \times 10^{7}$ cells was injected intravenously into sex-matched C57BL/ 6 recipient mice. One hour after injection, recipient mice were euthanized, and blood, lymph nodes, and spleen were collected. The ratios of Dko to WT $\mathrm{CD}^{+} \mathrm{T}$ cells were measured. To test naive $\mathrm{T}$ cell homing, peripheral lymph node (subiliac, auxiliary, and cervical) cells were collected from B6.SJL (CD45.1 $1^{+}$and CRK/CRKL Dko Rosa-YFP (CD45.2+) mice, mixed at a ratio of 1:1, and injected into $\mathrm{C} 57 \mathrm{BL} / 6$ recipient mice. Simultaneously, peripheral lymph node cells isolated from WT littermate control mice $\left(\mathrm{CD} 45.2^{+}\right)$were labeled with $0.2 \mu \mathrm{M}$ CFSE, mixed with B6.SJL cells at a ratio of 1:1, and injected into different recipient mice. One hour after adoptive transfer, recipient mice were euthanized; blood, lymph nodes, and spleens were collected and the frequency of transferred naive $\mathrm{T}$ cells $\left(\mathrm{CD} 44^{\text {lo }}, \mathrm{CD} 62 \mathrm{~L}^{\text {hi }}\right)$ was quantified by flow cytometry. The inflammation assay was performed as previously described (25). To induce a cutaneous inflammation, $0.5 \%$ DNFB was dissolved in acetone-olive oil (4:1) and applied to recipient mice (C57BL/6 mice) by skin painting on day -21 and day -20 . On day -1 , recipient mice were challenged with $0.3 \%$ DNFB. WT or CRK/CRKL Dko Th1 cells were labeled with $1 \mu \mathrm{M}$ CFSE or $5 \mu \mathrm{M}$ CMTMR and mixed at a ratio of $1: 1$, and $1 \times 10^{7}$ to $2 \times 10^{7}$ $\mathrm{T}$ cells were injected intravenously. Twenty-four hours after adoptive transfer, recipient mice were euthanized; blood, lymph nodes, spleens, and skin were collected; and the frequency of transferred WT and CRK/ CRKL Dko T cells was quantified by flow cytometry. All inflammation experiments were performed side-by-side with reciprocal staining. Each in vivo experiment was conducted with pooled donor cells from at least 3 mice per genotype to minimize donor-to-donor variations. The migration index was calculated as Dko adoptively transferred/WT adoptively transferred, normalized to Dko input/WT input.

GVHD and GVL. For GVHD, CD4 ${ }^{+}$T cells were purified from WT or CRK/CRKL Dko mice, mixed with $\mathrm{T}$ cell-depleted bone marrow (TCD-BM) cells that were prepared from $\mathrm{C} 57 \mathrm{BL} / 6$ mice, and injected into lethally irradiated BALB/c mice $(8 \mathrm{~Gy} \times 1)$. Body weight and GVHD scores were assessed as described previously (62). For GVL, purified $\mathrm{CD}^{+} \mathrm{T}$ cells from WT or CRK/CRKL Dko mice were mixed with TCD$\mathrm{BM}$ and A2O cells that express luciferase and injected into irradiated $\mathrm{BALB} / \mathrm{c}$ mice. The bioluminescent signal intensity was determined after intraperitoneal injection of $4.5 \mathrm{mg}$ Firefly D-luciferin (Biosynth) using the IVIS 200 system (Xenogen). The survival and body weight changes of the recipient mice were assessed.

To assess $\mathrm{T}$ cell migration during the GVHD, $\mathrm{CD} 8^{+} \mathrm{T}$ cells were sorted by flow cytometry from WT or CRK/CRKL Dko mice (CD45.2+, Thy1.1 $1^{-}$and mixed 1:1 with FACS-sorted $\mathrm{CD}^{+} \mathrm{T}$ cells from B6.SJL mice (CD45.1 $1^{+}$, Thy $\left.1.1^{-}\right)$. These $\mathrm{CD} 8^{+} \mathrm{T}$ cells were injected together with TCD-BM (Thy1.1 $1^{+}$into lethally irradiated BALB/c mice. On day 10-12, the recipient mice were sacrificed, and the spleen and liver were harvested. The ratio of adoptively transferred $\mathrm{CD} 8^{+} \mathrm{T}$ cells (all $\mathrm{H} 2 \mathrm{~K}^{\mathrm{b}+}$, Thy1.1 $1^{-}$) from experimental (WT or Dko, both CD45.2 ${ }^{+}$) versus competitor (B6.SJL, CD45.1 ${ }^{+}$) mice was determined by flow cytometry.

Statistics. Bar graphs represent mean \pm SD. Data were analyzed using Excel or Prism 5.0 (GraphPad Software). Statistical significance was tested using paired or unpaired 2-tailed Student's $t$ tests or ANOVA as appropriate, with $P<0.05$ set as a cutoff for significance.

Study approval. Animals were maintained and procedures were performed with approval of the IACUCs of the Children's Hospital of Philadelphia and the University of Pennsylvania School of Medicine.

\section{Acknowledgments}

We thank Drew Comrie and other members of the Burkhardt laboratory for helpful discussions and critical reading of the manuscript. We also thank the flow cytometry cores at the University of Pennsylvania and the Children's Hospital of Philadelphia for valuable assistance. This work was supported by NIH grant K01 AR057577 to Y. Huang, R01 AI065644 to J.K. Burkhardt, T32 HL007775 to M. Karimi, T32 TCA009140 to N.H. Roy, and R01AR056780 to G.F. Debes. This work was also supported by a Pennsylvania Department of Health CURE formulary grant (SAP\#4100047628) to T. Curran.

Address correspondence to: Yanping Huang, Department of Pathology and Laboratory Medicine, Children's Hospital of Philadelphia, 3615 Civic Center Boulevard, 815 Abramson Research Center, Philadelphia, Pennsylvania 19104, USA. Phone: 267.426.5523; E-mail: huangy@email.chop.edu. Or to: Janis K. Burkhardt, Department of Pathology and Laboratory Medicine, Children's Hospital of Philadelphia, 3615 Civic Center Boulevard, 816D Abramson Research Center, Philadelphia, Pennsylvania 19104, USA. Phone: 267.426.5410; E-mail: jburkhar@mail.med.upenn.edu.

Yi Zhang's present address is: Department of Microbiology \& Immunology, Fels Institute for Cancer Research \& Molecular Biology, Temple University School of Medicine, Philadelphia, Pennsylvania, USA.
1. Masopust D, Schenkel JM. The integration of T cell migration, differentiation function. Nat Rev Immunol. 2013;13(5):309-320.

2. Ley K, Laudanna C, Cybulsky MI, Nourshargh S. Getting to the site of inflammation: the leukocyte adhesion cascade updated. Nat Rev Immunol. 2007;7(9):678-689.

3. Blazar BR, Murphy WJ, Abedi M. Advances in graft-versus-host disease biology and therapy. Nat Rev Immunol. 2012;12(6):443-458.

4. Birge RB, Kalodimos C, Inagaki F, Tanaka S. Crk and CrkL adaptor proteins: networks for physiological and pathological signaling. Cell Commun
Signal. 2009;7:13.

5. Klemke RL, Leng J, Molander R, Brooks PC, Vuori K, Cheresh DA. CAS/Crk coupling serves as a "molecular switch" for induction of cell migration. JCell Biol. 1998;140(4):961-972.

6. Kobashigawa Y, et al. Structural basis for the transforming activity of human cancer-related signaling adaptor protein CRK. Nat Struct Mol Biol. 2007;14(6):503-510.

7. Feller SM, Knudsen B, Hanafusa H. c-Abl kinase regulates the protein binding activity of c-Crk. EMBO J. 1994;13(10):2341-2351.

8. de Jong R, ten Hoeve J, Heisterkamp N, Groffen J.
Tyrosine 207 in CRKL is the BCR/ABL phosphorylation site. Oncogene. 1997;14(5):507-513.

9. Matsuda M, Tanaka S, Nagata S, Kojima A, Kurata T, Shibuya M. Two species of human CRK cDNA encode proteins with distinct biological activities. Mol Cell Biol. 1992;12(8):3482-3489.

10. Guris DL, Fantes J, Tara D, Druker BJ, Imamoto A. Mice lacking the homologue of the human 22q11.2 gene CRKL phenocopy neurocristopathies of DiGeorge syndrome. Nat Genet. 2001;27(3):293-298.

11. Park TJ, Boyd K, Curran T. Cardiovascular and craniofacial defects in Crk-null mice. Mol Cell 
Biol. 2006;26(16):6272-6782.

12. Peterson AC, Marks RE, Fields PE, Imamoto A, Gajewski TF. T cell development and function in CrkL-deficient mice. Eur J Immunol. 2003;33(10):2687-2695.

13. Nolz JC, et al. The WAVE2 complex regulates $\mathrm{T}$ cell receptor signaling to integrins via AblCrkL-C3G-mediated activation of Rap1. J Cell Biol. 2008;182(6):1231-1244.

14. Park TJ, Curran T. Crk and Crk-like play essential overlapping roles downstream of disabled-1 in the Reelin pathway. J Neurosci. 2008;28(50):13551-13562.

15. Srinivas $S$, et al. Cre reporter strains produced by targeted insertion of EYFP and ECFP into the ROSA26 locus. BMC Dev Biol. 2001;1:4.

16. Letschka T, et al. PKC-theta selectively controls the adhesion-stimulating molecule Rap1. Blood. 2008;112(12):4617-4627.

17. Smith A, Bracke M, Leitinger B, Porter JC, Hogg N. LFA-1-induced T cell migration on ICAM-1 involves regulation of MLCK-mediated attachment ROCK-dependent detachment. J Cell Sci. 2003;116(pt 15):3123-3133.

18. Stein JV, et al. The CC chemokine thymusderived chemotactic agent 4 (TCA-4, secondary lymphoid tissue chemokine, 6Ckine, exodus-2) triggers lymphocyte function-associated antigen 1-mediated arrest of rolling $\mathrm{T}$ lymphocytes in peripheral lymph node high endothelial venules. JExp Med.2000;191(1):61-76.

19. Warnock RA, Campbell JJ, Dorf ME, Matsuzawa A, McEvoy LM, Butcher EC. The role of chemokines in the microenvironmental control of $\mathrm{T}$ versus B cell arrest in Peyer's patch high endothelial venules. J Exp Med. 2000;191(1):77-88.

20. Groom JR, Luster AD. CXCR3 ligands: redundant, collaborative and antagonistic functions. Immunol Cell Biol. 2011;89(2):207-215.

21. Bai Z, et al. CXC chemokine ligand 12 promotes CCR7-dependent naive $\mathrm{T}$ cell trafficking to lymph nodes Peyer's patches. JImmunol. 2009;182(3):1287-1295.

22. Lämmermann $\mathrm{T}$, et al. Rapid leukocyte migration by integrin-independent flowing and squeezing. Nature. 2008;453(7191):51-55.

23. Kanda $\mathrm{H}$, et al. Ligation of the $\mathrm{T}$ cell antigen receptor induces tyrosine phosphorylation of p105CasL, a member of the p130Cas-related docking protein family, its subsequent binding to the Src homology 2 domain of c-Crk. Eur JImmunol. 1997;27(8):2113-2117.

24. Shishido $\mathrm{T}$, et al. Crk family adaptor proteins trans-activate c-Abl kinase. Genes Cells. 2001;6(5):431-440.

25. Austrup F, et al. P- and E-selectin mediate recruitment of T-helper-1 but not T-helper- 2 cells into inflammed tissues. Nature. 1997;385(6611):81-83.

26. Reshef R, et al. Blockade of lymphocyte chemotaxis in visceral graft-versus-host disease. $N$ Engl JMed. 2012;367(2):135-145.

27. Shimonaka M, et al. Rap1 translates chemokine signals to integrin activation, cell polarization, and motility across vascular endothelium under flow. J Cell Biol. 2003;161(2):417-427.

28. Zhang W, Shao Y, Fang D, Huang J, Jeon MS, Liu YC. Negative regulation of $\mathrm{T}$ cell antigen receptormediated Crk-L-C3G signaling cell adhesion by
Cbl-b. J Biol Chem. 2003;278(26):23978-23983.

29. Ichiba T, et al. Enhancement of guaninenucleotide exchange activity of C3G for Rap1 by the expression of Crk, CrkL, Grb2.J Biol Chem. 1997;272(35):22215-22220.

30. Ichiba T, et al. Activation of C3G guanine nucleotide exchange factor for Rap 1 by phosphorylation of tyrosine 504. JBiol Chem. 1999;274(20):14376-14381.

31. Gérard A, Mertens AE, van der Kammen RA, Collard JG. The Par polarity complex regulates Rap1and chemokine-induced $\mathrm{T}$ cell polarization. J Cell Biol. 2007;176(6):863-875.

32. Sakakibara A, Hattori S. Chat, a Cas/HEF1associated adaptor protein that integrates multiple signaling pathways. J Biol Chem . 2000;275(9):6404-6410.

33. Regelmann AG, Danzl NM, Wanjalla C, Alexandropoulos $\mathrm{K}$. The hematopoietic isoform of Cas-Hef1-associated signal transducer regulates chemokine-induced inside-out signaling $\mathrm{T}$ cell trafficking. Immunity. 2006;25(6):907-918.

34. Li L, Guris DL, Okura M, Imamoto A. Translocation of CrkL to focal adhesions mediates integrininduced migration downstream of Src family kinases. Mol Cell Biol. 2003;23(8):2883-2892.

35. Nishihara H, et al. Non-adherent cell-specific expression of DOCK2, a member of the human CDM-family proteins. Biochim Biophys Acta. 1999;1452(2):179-187.

36. Nishihara H, et al. DOCK2 associates with CrkL and regulates Rac1 in human leukemia cell lines. Blood. 2002;100(12):3968-3974.

37. Fukui Y, et al. Haematopoietic cell-specific CDM family protein DOCK2 is essential for lymphocyte migration. Nature. 2001;412(6849):826-831.

38. Nombela-Arrieta C, et al. Differential requirements for DOCK2 and phosphoinositide-3kinase $\gamma$ during $\mathrm{T} B$ lymphocyte homing. Immunity. 2004;21(3):429-441.

39. Shulman Z, et al. DOCK 2 regulates chemokine-triggered lateral lymphocyte motility but not transendothelial migration. Blood. 2006;108(7):2150-2158.

40. Shulman Z, et al. Lymphocyte crawling and transendothelial migration require chemokine triggering of high-affinity LFA-1 integrin. Immunity. 2009;30(3):384-396.

41. Huang Y, Comiskey EO, Dupree RS, Li S, Koleske AJ, Burkhardt JK. The c-Abl tyrosine kinase regulates actin remodeling at the immune synapse. Blood. 2008;112(1):111-119.

42. Gu JJ, Lavau CP, Pugacheva E, Soderblom EJ, Moseley MA, Pendergast AM. Abl family kinases modulate $\mathrm{T}$ cell-mediated inflammation and chemokine-induced migration through the adaptor HEF1 and the GTPase Rap1. Sci Signal. 2012;5(233):ra51.

43. Antoku S, Mayer BJ. Distinct roles for Crk adaptor isoforms in actin reorganization induced by extracellular signals. J Cell Sci. 2009; 122(pt 22):4228-4238.

44. Park TJ, Curran T. Essential roles of Crk and CrkL in fibroblast structure and motility. Oncogene. 2014;33(43):5121-5132.

45. Vestweber D, Broermann A, Schulte D. Control of endothelial barrier function by regulating vascular endothelial-cadherin. Curr Opin Hematol.
2010;17(3):230-236.

46. Muller WA. How endothelial cells regulate transmigration of leukocytes in the inflammatory response. Am J Pathol. 2014;184(4):886-896.

47. Mionnet $\mathrm{C}$, et al. High endothelial venules as traffic control points maintaining lymphocyte population homeostasis in lymph nodes. Blood. 2011;118(23):6115-6122.

48. Pfeiffer F, et al. Distinct molecular composition of blood and lymphatic vascular endothelial cell junctions establishes specific functional barriers within the peripheral lymph node. Eur J Immunol. 2008;38(8):2142-2155.

49. Bai Z, et al. Constitutive lymphocyte transmigration across the basal lamina of high endothelial venules is regulated by the autotaxin/lysophosphatidic acid axis. JImmunol. 2013;190(5):2036-2048.

50. Liang Y, et al. $\beta 2$ integrins separate graft-versushost disease and graft-versus-leukemia effects. Blood. 2008;111(2):954-962.

51. Coghill JM, et al. Separation of graft-versus-host disease from graft-versus-leukemia responses by targeting CC-chemokine receptor 7 on donor $\mathrm{T}$ cells. Blood. 2010;115(23):4914-4922.

52. Valenzuela JO, et al. PKCtheta is required for alloreactivity and GVHD but not for immune responses toward leukemia and infection in mice. J Clin Invest. 2009;119(12):3774-3786.

53. Grabbe $S$, et al. Beta 2 integrins are required for skin homing of primed $\mathrm{T}$ cells but not for priming naive T cells. JClin Invest. 2002;109(2):183-192.

54. Cannon JL, et al. PKCtheta regulates T cell motility via ezrin-radixin-moesin localization to the uropod. PLoS One. 2013;8(11):e78940.

55. Lobatón T, Vermeire S, Van Assche G, Rutgeerts P. Review article: anti-adhesion therapies for inflammatory bowel disease. Aliment Pharmacol Ther. 2014;39(6):579-594.

56. Cross AH, Naismith RT. Established and novel disease-modifying treatments in multiple sclerosis. J Intern Med. 2014;275(4):350-363.

57. Pear WS, et al. Efficient and rapid induction of a chronic myelogenous leukemia-like myeloproliferative disease in mice receiving P210 bcr/abl-transduced bone marrow. Blood. 1998;92(10):3780-3792.

58. Huang Y, Norton DD, Precht P, Martindale JL, Burkhardt JK, Wange RL. Deficiency of ADAP/ Fyb/SLAP-130 destabilizes SKAP55 in Jurkat T cells. J Biol Chem. 2005;280(25):23576-23583.

59. Bird JJ, et al. Helper T cell differentiation is controlled by the cell cycle. Immunity. 1998;9(2):229-237.

60. Banerjee P, Lenz D, Robinson JP, Rickus JL, Bhunia AK. A novel and simple cell-based detection system with a collagen-encapsulated B-lymphocyte cell line as a biosensor for rapid detection of pathogens and toxins. Lab Invest. 2008;88(2):196-206.

61. Zengel P, Nguyen-Hoang A, Schildhammer C, Zantl R, Kahl V, Horn E. mu-Slide Chemotaxis: a new chamber for long-term chemotaxis studies. BMC Cell Biol. 2011;12:21.

62. Anderson BE, McNiff JM, Jain D, Blazar BR, Shlomchik WD, Shlomchik MJ. Distinct roles for donor- and host-derived antigen-presenting cells and costimulatory molecules in murine chronic graft-versus-host disease: requirements depend on target organ. Blood. 2005;105(5):2227-2234. 